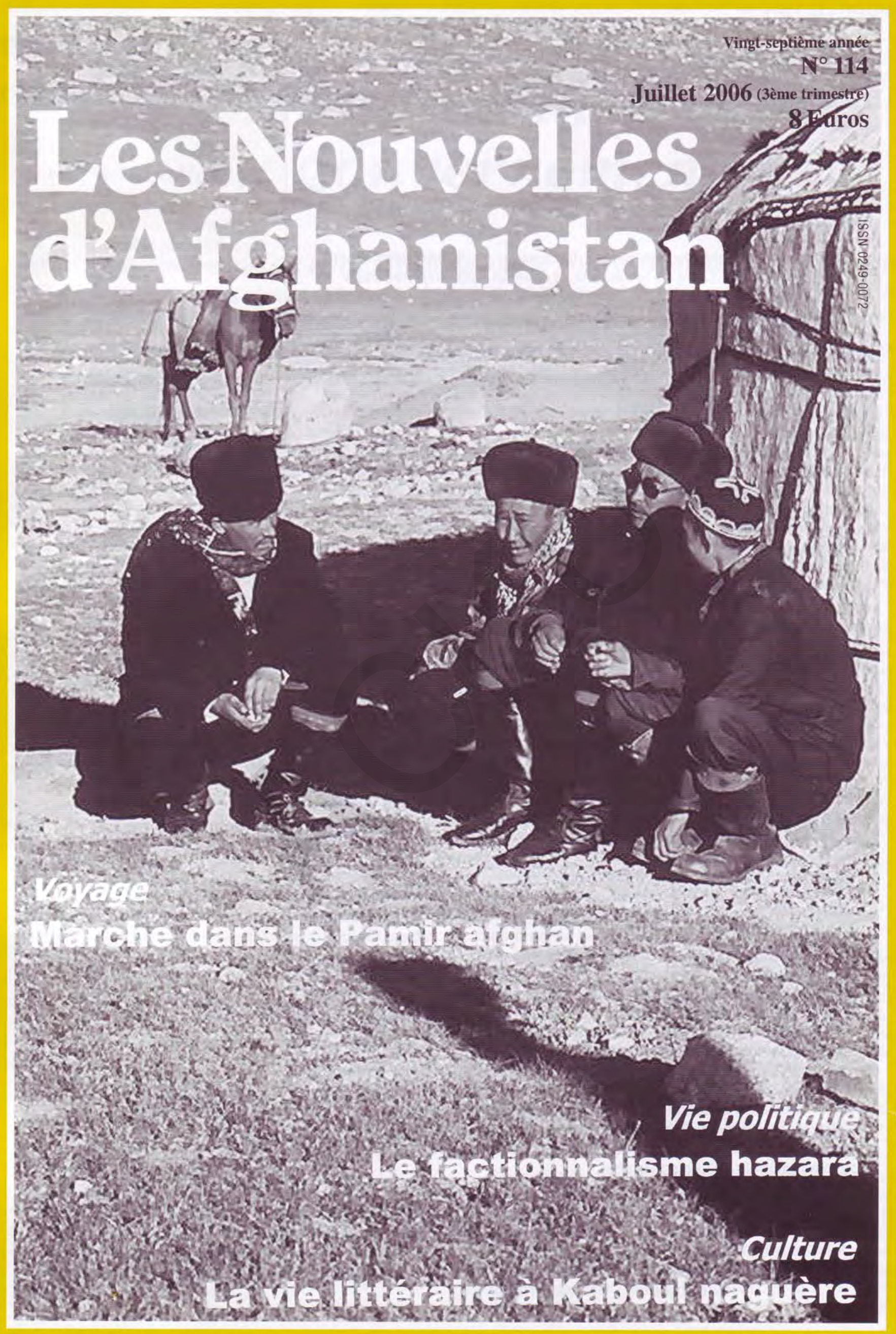




\section{Malentendus}

eux problématiques continuent de dominer les débats concernant

l'Afghanistan. Celle de la sécurité et celle de l'aide internationale.

Le développement des incidents armés et l'augmentation du nombre des victimes donnent le sentiment d'une sérieuse dégradation. Cependant, l'interprétation des faits est délicate. Soulignons d'abord que les incidents restent concentrés dans une poignée de provinces du sud et de l'est. Dans le reste du pays, la situation semble analogue à ce qu'elle était l'an dernier. Les émeutes fin mai à Kaboul ont contribué à alarmer les esprits, mais rien n'indique qu'elles soient significatives d'une dégradation généralisée de la sécurité.

En ce qui concerne le sud, deux analyses contradictoires existent. La première est pessimiste. L'influence des Tâlebân est croissante et le soutien que leur apporte la population est réel, lié aux désillusions de la reconstruction. La seconde impute au contraire l'augmentation des combats à la conjoncture militaire. L'armée afghane, plus opérationnelle, va davantage au contact. Et les Tâlebân multiplient les attaques dans l'espoir qu'en faisant vite des morts parmi les forces étrangères, celles-ci plieront bagage sans tarder. A ceci s'ajoute la lutte contre le pavot: les trafiquants joignent leurs forces à celles des Tâlebân, pour éviter une présence internationale dans des régions jusqu'à présent loin du contrôle gouvernemental. Mais si les forces internationales font preuve de détermination, les Tâlebân, selon cette deuxième analyse, ne pourront pas tenir longtemps.

Les événements ne tarderont pas à départager les tenants de ces deux analyses. Un élément important d'appréciation serait de connaître le sentiment profond de la population. Mais ce sentiment, à supposer qu'il soit univoque, est difficile à percevoir. L'interview par un journaliste étranger de tel cordonnier ou conducteur de taxi n'y suffit pas.

Quoi qu'il en soit la lutte anti-Tâlebân ne pourra se gagner qu'en tenant mieux compte des aspirations de la population. Les stratèges internationaux, y compris américains, semblent en avoir davantage conscience. II serait temps, car le manque de discernement des forces américaines dans leur comportement avec la population a eu un impact très négatif sur la perception qu'ont les Afghans de l'aide internationale.

Le cadre de cet éditorial ne permet que d'évoquer incidemment le débat concernant cette aide. Largement relayée par les hommes politiques et par les médias, l'idée prévaut qu'elle se perd dans les sables. Ce discours repose sur une part de malentendu. De nombreux aspects de l'aide internationale peuvent et doivent être critiqués et révisés afin de la rendre plus efficace. Cependant il serait injuste de dire que l'Afghan moyen reste à l'écart de la reconstruction. D'une part, le nombre des Afghans dont le niveau de vie s'est effectivement amélioré n'est sans doute pas négligeable. Ensuite, beaucoup bénéficient directement, mais non monétairement, des effets de la reconstruction, que ce soit par l'accès de leurs enfants à l'école, le développement du réseau des cliniques, l'amélioration des routes etc. II est certes essentiel que chacun voie son niveau de vie personnel s'améliorer. II faut aussi dénoncer les écarts choquants entre ceux qui s'enrichissent et les autres. Mais une analyse plus objective des effets de l'aide internationale est indispensable.

Etienne GILLE Le 17 juin

\section{Site internet: www.afrane.org}

\section{SOMMAIRE $\mathbf{N}^{\circ} 114$}

VIE POLITIQUE

La constitution laborieuse

du gouvernement 3

Le fractionnalisme hazara

De la guerre civile au processus démocratique

par Alessandro MONSUTTI $-6$

PROVINCE

Voyage au Pamir afghan par Régis LEFEVRE 9

EXIL

Quelque part dans Paris...

des oiseaux sans nid par Julie GOISLARD $-15$

Khaled Hosseini

L'itinéraire d'un romancier afghan par Jack CHABOUD 16

CULTURE

La botte et la plume

La vie littéraire à Kaboul avant et pendant l'occupation

par Nadjib MANALAI 18

Adieu à un poète reporter par Jéróme BONY $-21$

DERNIERES NOUVELLES

Chronologie, brèves, bibliographie $\_23$

Photo de couverture: Wakhan, 2005, campement de Sare Mo Kol. Photo Régis Lefèvre

\footnotetext{
Adresse E-mail afrane@afrane.org
}

Les Nouvelles d'Afghanistan 16. Passage de la Main d'Or - 75011 PARIS 


\title{
La constitution laborieuse du gouvernement
}

\author{
Pour la première fois de l'bistoire afghane, le gouvernement nouvellement \\ constitué a été soumis à un vote de l'Assemblée. Le 6 mai, vingt ministres \\ présentés par le président Karzaï ont été ainsi acceptés par l'Assemblée \\ nationale, tandis que cinq candidats n'ont pas obtenu la confiance. \\ Le président devra présenter de nouveaux candidats.
}

Le président Karzaï avait soumis une liste de ministrables au Parlement le 25 mars. L'événement alors le plus commenté était le remplacement d'Abdullah Abdullah, l'ancien ministre des Affaires étrangères, par M. Dadfar Spanta. Les deux hommes sont issus de milieux politiques très différents. M. Abdullah Abdullah fait partie de la mouvance des " Pandjchiris ". Il a représenté l'Afghanistan dans les forums internationaux depuis la chute du régime communiste au début des années 90. Avec lui, c'est le dernier représentant de la troika des Pandjchiris (Maréchal Fahim, Qanouni et lui-même) qui quitte le gouvernement. M. Spanta, originaire de Hérat, faisait quant à lui partie dans sa jeunesse du mouvement " La flamme éternelle " (chole djawid), courant marxiste antisoviétique. Il a ensuite longtemps vécu en Allemagne. Il ne dispose pas de réseau d'influence en Afghanistan. L'explication de ce changement à la tête de la diplomatie afghane n'a pas été donnée. Selon certains, les récentes déclarations conciliantes de M. Abdullah au sujet de l'Iran auraient irrité les Etats-Unis. Spanta a, dès sa prise de fonction, insisté sur la nécessité de rétablir des bonnes relations avec le Pakistan. Il n'est donc pas impossible que M. Karzaï ait voulu faire un geste en direction de ce pays en se séparant de M. Abdullah (qui a refusé les autres postes moins importants qui lui étaient proposés au sein du cabinet). On dit aussi que $M$. Karzaï souhaiterait procéder à un mouvement parmi les ambassadeurs afghans, mais que M. Abdullah s'y opposait. Celui-ci est resté très discret sur les raisons de son remplacement et n'a pas semblé vouloir envenimé les choses. On peut noter que $M$. Spanta a été très bien accueilli par le Parlement afghan, puisqu'il a recueilli les deux tiers des suffrages.

\section{Le processus d'audition}

C'est donc la première fois qu'un gouvernement afghan avait à se soumettre à l'approbation du Parlement. Le manque de précédent a obligé l'assemblée à tâtonner à plusieurs reprises. Certains observateurs attentifs de la politique afghane ont été impressionnés par le rôle joué par le Président de l'assemblée, Younos Qanouni, au cours de ces débats difficiles. Disposant d'un solide passé de résistant, beaucoup moins suspect que d'autres de tentations ethniques ou d'extrémisme, il prépare sans doute, au Parlement, son avenir politique en tant que seul opposant démocratique crédible et donc éventuel successeur de Karzaï à la tête de l'Etat afghan. Il semble avoir cherché à jouer le rôle d'arbitre se plaçant au dessus des débats, tentant ainsi de se donner une dimension véritablement nationale.
Dans un premier temps, les députés ont refusé de procéder au vote de confiance, car ils considéraient avoir trop peu d'informations sur les candidats. L'administration présidentielle leur a alors fourni une biographie détaillée de chacun d'entre eux. Puis, pendant près de 15 jours, les députés ont auditionné les personnalités proposées. Après s'être présenté et avoir décrit brièvement son programme, chaque candidat a été interrogé par les dix-huit présidents de commission. Cette phase était retransmise en direct par les chaînes de télévision et semble avoir été suivie par la population afghane.

Cette procédure n'a pas été de tout repos pour les candidats, notamment pour Sayyed Makhdoum Rahin. Pressenti pour le poste de ministre de la Culture et de la Jeunesse, il a été l'objet d'attaques des fondamentalistes qui lui ont reproché d'avoir autorisé les chaînes de télévision privées à diffuser des films indiens dans lesquels apparaissent des actrices trop dénudées à leurs yeux. Ces mêmes ultraconservateurs n'ont pas supporté de le voir apprécier le talent d'une chanteuse originaire du Tadjikistan et d'avoir applaudi. M. Rahin a également été accusé d'avoir privilégié le dari au détriment de la langue pachtou.

Les raisons qui ont conduit au rejet de $\mathrm{M}$. Amin Farhang pour le poste de ministre de l'Economie qu'il occupait déjà, alors que c'est un homme respecté et compétent, ne sont pas ressorties dans la presse.

Les ministres-candidats ont fait l'objet d'une campagne calomnieuse orchestrée par Hafez Abdoul Mansour, rédacteur en chef de Payam-e Modjahed, hebdomadaire très proche du Djamiat-e Islami. Mansour, qui fut candidat à la présidentielle d'octobre 2004 (où il obtint moins de $1 \%$ des suffrages), a publié la liste des ministres proposés en l'accompagnant d'une série d'accusations détournement de fonds, corruption, manque de piété, manque de qualifications, incompétence, double nationalité, parenté avec des Juifs ou liens avec les services secrets pakistanais.

Ces critiques acerbes venant d'une partie de la presse ne sont certes pas à l'honneur de celle-ci compte tenu des accusations lancées mais elles illustrent par leurs outrances même une relative ouverture de l'espace public afghan. On peut espérer que suivant cette voie (si possible de manière moins tortueuse), d'autres médias s'ils s'intéressent aux proches de Payam-e Modjahed, bénéficieront de la même tolérance. 
Ramazan Bachardost, ancien ministre du Plan du président Karzaï, s'est également distingué par sa critique farouche du processus ${ }^{1}$. Il n'a eu de cesse de déclarer que le président ne s'était pas conformé à la Constitution en présentant son Cabinet au Parlement plus de trente jours après la session inaugurale de celui-ci. En signe de protestation, Ramazan Bachardost a quitté l'hémicycle et n'a plus siégé pendant quinze jours. À son retour, il a lancé une nouvelle charge, accusant certains des ministres pressentis d'avoir une double nationalité. La virulence de ses propos a conduit le président de l'Assemblée, Younos Qanouni, à couper son microphone. En réponse, le député a, une nouvelle fois, claqué la porte.

Ces remises en cause par certains membres du Parlement, et notamment Ramazan Bachardost, montrent à la fois leurs limites sur la forme, le processus ayant été mené de façon régulière, et sur le fond car le Parlement a exercé le rôle essentiel qui lui avait été dévolu (et qui paraissait bien complexe à la lecture de la constitution). Preuve sans doute que si certains députés ont fait preuve d'un grand sectarisme, la plupart se sont attachés à étudier avec sérieux les candidatures des ministres pour permettre aux institutions, en construction depuis la première Loya Djirga de 2002 et maintenant complètement installées, d'enfin fonctionner. Une telle approche montre, par elle-même, une ouverture des esprits dans l'opinion afghane.

\section{Le vote du 20 avril}

Les députés ont obtenu de se prononcer candidat par candidat par un vote à bulletin secret, alors que $\mathrm{H}$. Karzaï aurait bien sûr préféré un vote global.

Le vote du 20 avril a permis d'entériner la nomination de 17 ministres et le rejet de la candidature de cinq autres, notamment l'unique ministre femme, et les ministres des finances et de la culture. En revanche, le sort de trois ministres, Amirzai Sangin, Youssof Pachtoun et Mohammad Akbar Akbar, a posé problème en raison d'un débat sur la définition de la majorité. En effet, si les trois hommes ont obtenu la majorité des votes exprimés, ils n'ont pas eu la majorité absolue des inscrits. L'Assemblée n'arrivant pas à se mettre d'accord sur le type de majorité qui était requis, elle a remis étrangement le dossier au Président Karzaï qui a lui même porté l'affaire devant la Cour suprême. Celle-ci a tranché en faveur de l'approbation des trois candidats en balance.

\section{Conclusion}

Les différents votes de l'assemblée ne sont pas faciles à analyser, car aucune ligne ni pro-, ni anti-Karzaï ne s'est clairement dessinée. En réalité, les députés semblent s'être prononcés au cas par cas, en dehors de toute analyse globale de la future politique gouvernementale. D'un côté, Karzaï a obtenu sans grosse difficulté la nomination de $80 \%$ de ses candidats, et notamment des candidats aux postes clés de la Défense, de l'Intérieur et des Finances. Mais d'un autre, les députés ont voulu manifester leur indépendance par rapport à l'exécutif, et l'ont mis en difficulté pour des nominations non moins sensibles puisqu'elles touchent à la culture et à la condition féminine. Selon un député de
Sayyed Makhdoum Rahin, pressent comme ministre de la Culture, n'a pas reçu l'approbation du Parlement. Photo V. Marigo

Séance au Parlement. C'est la première fois qu'un gouvemement afghan a à se soumettre à l'approbation du

Parlement. Photo EPA

Younos Qanouni, Président de l'assemblée nationale, semble avoir cherché à

jouer un rôle d'arbitre en se plaçant au dessus des débats. Photo EPA
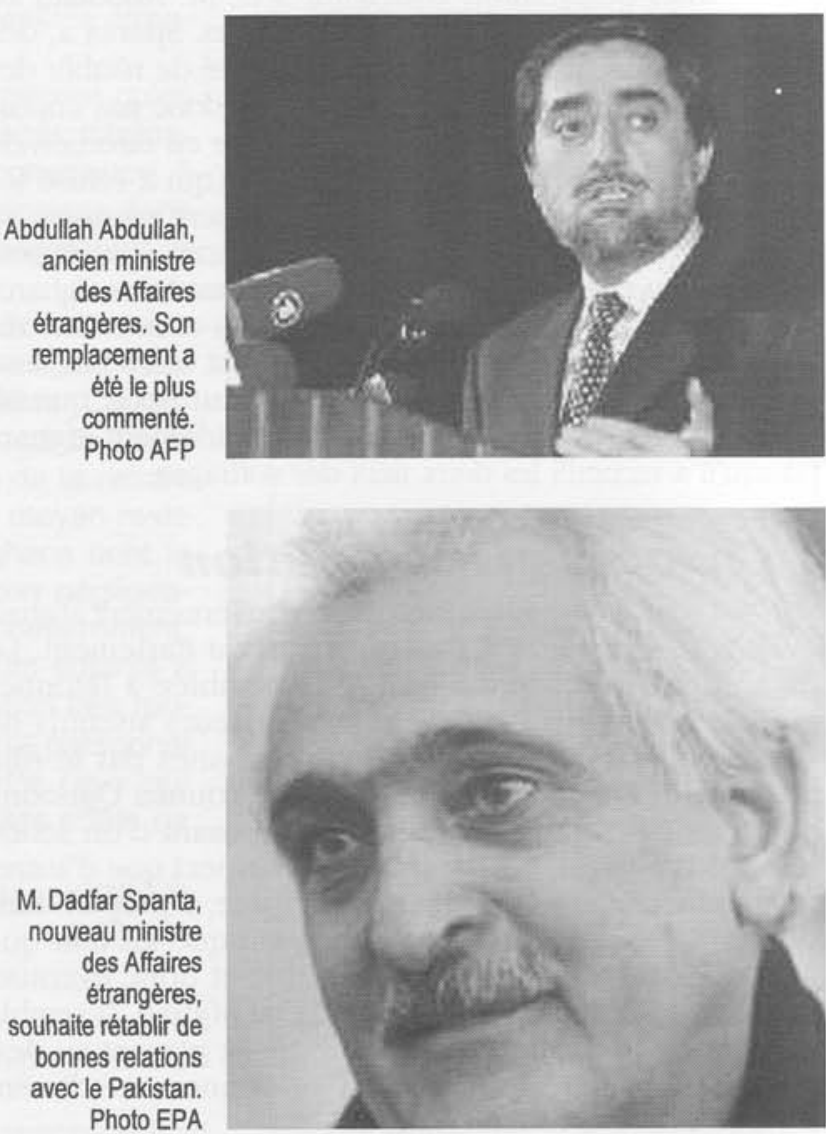


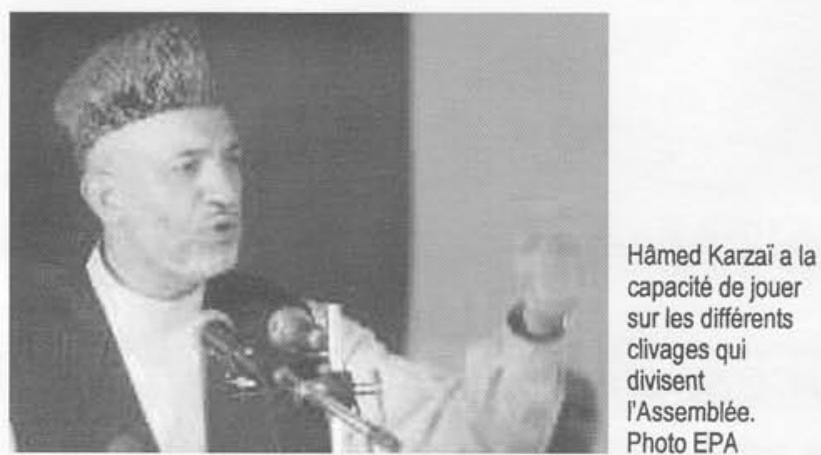

Zaboul, le fameux Salam Roketi, "il est clair que Karzaï a gagné. Mais nous devions rejeter quelques noms par souci d'équilibre." ! M. Fazel Oria, responsable du journal Payam, dit en substance la même chose quand il estime que "les cinq ministres qui ont échoué n'ont pas été acceptés parce qu'ils n'avaient ni le soutien du Parlement, ni réellement celui de Karzaï ". Quoi qu'il

\section{Le cabinet proposé par Hâmed Karzaï avec le résultat des votes}

Ministre de la Défense : Abdoul Ràim Wardak (166 contre 62) Ministre des Affaires étrangères : *Rangin Dadfar Spanta (150 contre 75)

Ministre des Finances : Anwarul Haq Ahadi (168 contre 67)

Ministre de l'Intérieur: * Ingénieur Zarar Ahmad Moqbel (185 contre 51)

Ministre de la Réhabilitation et du Développement rural : *Ehsan Zia (206 contre 27)

Ministre des Transports et de l'Aviation : *Gul Hussain Ahmadi (105 contre 116)

Ministre des Réfugiés : *Professeur Akbar Akbar (118 contre 102)

Ministre de la Condition féminine : *Dr Soraya Rahim Sobhrang (98 contre 128)

Ministre du Commerce et de I'Industrie : *Mohammad Haïdar Reza (99 contre 123)

Ministre de l'Education Supérieure : Azam Dadfar (145 contre

81) (ancien ministre aux Réfugiés)

Ministre de l'Education: Hanif Atmar (185 contre 47) (ancien ministre du développement rural)

Ministre des Martyrs, des Handicapés et des Affaires Sociales : Nour Mohammad Qarqin (194 contre 41) (ancien ministre de I'Education)

Ministre de la Justice : Sarwar Danesh (166 contre 63)

Ministre des Communications : Amirzaï Sangin (120 contre 108)

Ministre de la Santé Publique : Sayyed Mohammad Amin Fatimi (217, contre 24 ; le mieux élu)

Ministre de l'Economie et du Travail : Mir Mohammad Amin Farhang (60 contre 154)

Ministre de la Culture et de la Jeunesse : Sayed Makhdoum Rahin (93 contre 131)

Ministre de la Ville : Youssof Pachtoun (121 contre 107)

Ministre des Travaux Publics : Ingénieur Sohrab Ali Safari (133 contre 96)

Ministre de l'Eau et de l'Energie : Ismaël Khan (133 contre 90)

Ministre des Frontières et des Affaires Tribales: Karim Barahoui (176 contre 55)

Ministre des Affaires Religieuses : Nematullah Shahrani (145 contre 84)

Ministre de la Lutte Anti- Drogue : Habiboullah Qaderi (135 contre 95)

Ministre de I'Agriculture et de I'Irrigation : Obaidoullah Ramin (178 contre 58 )

Ministre des Mines: *Ingénieur Ibrahim Adel (128 contre 95)

(Les noms des nouveaux ministres sont précédés d'une *. Les ministres refusés sont en italique) en soit, il apparaît que, pour le moment du moins, les partisans de Karzaï sont majoritaires au Parlement. Ou tout au moins que Karzaï a la capacité de jouer sur les différents clivages qui divisent l'assemblée pour obtenir gain de cause sur les dossiers essentiels à ses yeux.

Les nouvelles propositions de Karzaï pour remplacer les ministres refusés (les députés ont le droit de refuser trois fois) et l'attitude de l'assemblée montreront s'il suffira au président afghan de faire des modifications cosmétiques, ou bien s'il devra donner des gages significatifs à la partie la plus conservatrice de l'assemblée.

Pour l'heure, il est encore hasardeux d'évaluer numériquement les différentes composantes du Parlement. Certains conservateurs contestés comme M. Sayyaf, font beaucoup parler d'eux. Il est difficile de mesurer leur réelle influence.

Faute d'avoir suivi les débats, il n'est pas possible non plus de se faire une idée exacte des questionnements principaux qui ont été faits aux différents candidats ministres. On ne dispose que de quelques dépêches d'agence, qui relèvent nécessairement les éléments les plus sensibles des interventions. Il est quand même navrant de constater qu'on a reproché à certains candidats la religion de leurs beaux-enfants. Le problème ethnique et linguistique semble aussi avoir été récurrent : tel candidat n'était-il pas suspect d'avoir favorisé son ethnie au détriment d'une autre? Selon des observateurs, l'intérêt national a du mal à transcender les questions régionales. L'opportunité tribunitienne et la démagogie poussent certains députés à des outrances qu'aucun frein institutionnel (parti politique ou risque de dissolution) n'est là pour empêcher.

On peut toutefois se demander si, confusément, le vote des députés ne traduit pas (même avec d'importantes distorsions) le jugement de la population afghane sur un certain nombre de secteurs qui ne sont pas considérés comme donnant des résultats assez convaincants dans le processus de reconstruction (rejet des titulaires de l'économie, des transports notamment) ou qui traduisent des débats très vifs au sein de la société afghane (échec des ministres de la culture et de la condition féminine). En ce sens, le rejet de la candidature d'Amin Farhang, ministre dont l'intégrité personnelle est bien connue mais qui souffre de la relative lenteur des grands travaux d'infrastructure, pourrait avoir une explication. Par ailleurs, le score finalement modeste de l'un des derniers grands chefs de la résistance, Ismael Khan (133 contre 90 et 19 abstentions et 2 votes nuls), montre que sans doute des évolutions en profondeur sont en cours en Afghanistan et que le Parlement s'en fait l'écho. Si cette tendance se confirme au cours des mois à venir, cela signifierait que, certes très lentement et avec des ratés, pour la première fois dans l'histoire afghane, le Parlement prendrait une véritable envergure, élément essentiel dans le complexe processus de démocratisation de l'Afghanistan.

E.G. et E.C. - D.

Note: De nombreuses informations de ce texte proviennent du site Bassirat.net

1 Ramazan Bachardoust définissait il n'y a pas si longtemps ses relations avec $\mathrm{H}$. Karzaï comme celles "d'un fils avec un père spirituel " (Les Nouvelles d'Afghanistan. $n^{\circ} 107$ ) 


\title{
Le factionnalisme bazara
}

\section{de la guerre civile au processus démocratique}

\author{
par Alessandro MONSUTTI*
}

\begin{abstract}
Pour comprendre les jeux politiques nationaux en Afghanistan, il est utile de regarder la logique des luttes de factions au niveau local. Les groupes etbniques sont le lieu de débats et de compétitions internes avant d'entrer éventuellement en conflit avec d'autres groupes. A. Monsutti ${ }^{1}$ étudie ici le cas des Hazaras.
\end{abstract}

La société afghane est extrêmement fragmentée et se caractérise par une multiplicité de sources de solidarité. L'ethnicisation - d'ailleurs toute relative - de la société afghane est plus le résultat que la cause de la guerre. Pour comprendre les jeux politiques nationaux il semble ainsi nécessaire d'aller au-delà d'une lecture centrée essentiellement sur les liens de parenté et l'affiliation ethnique. Il est plus fécond d'appréhender les groupes sociaux comme des arènes politiques où différents acteurs sont en compétition pour le pouvoir, et non comme des communautés au sein desquelles on pourrait trouver un niveau quasi naturel de solidarité où les intérêts de tous convergeraient. Une telle perspective permet de rendre intelligibles certains actes de violence, qui est dès lors prise comme un fait social. Il est en effet difficile d'imaginer que le retour à une certaine normalité signifie forcément, en Afghanistan, la fin de toute forme d'insécurité et de conflit.

L'Afghanistan, à l'instar de bien des sociétés du MoyenOrient, connaît des changements constants d'alliances et d'affiliations politiques. Les liens de solidarité, qu'ils soient fondés sur la parenté, le voisinage, l'appartenance ethnique, religieuse ou sociale, sont toujours fragiles et peuvent dégénérer en conflit, comme l'exprime le terme pachto tarbur, qui signifie cousin paternel, mais aussi ennemi ${ }^{2}$. Pour faire face à l'insécurité et diminuer les risques, les membres des groupes domestiques ont développé une logique de diversification des relations sociales, mais aussi des activités économiques et des affiliations politiques. Le factionnalisme est dès lors un élément constitutif du paysage politique afghan.

Le cas des Hazaras, dont certains leaders ont pourtant développé tout un discours de revendication ethniciste, n'échappe pas à cette logique factionnelle inhérente à l'anthropologie politique de l'Afghanistan.

\section{Les années 1980 : une guerre intestine}

L'Afghanistan s'est constitué au XVIIIe siècle par l'expansion guerrière des tribus pachtounes, qui se sont taillé un espace politique alors que les grands empires régionaux (Séfévides en Iran, Moghols en Inde,

- Anthropologue, Institut universitaire d'études du développement (Genève)
Chaỉbanides en Asie centrale) étaient en déclin. Au XIXe siècle, le pays sert d'Etat-tampon entre les empires britannique en Inde et russe en Asie centrale. Les frontières sont fixées à ce moment et ne connaîtront plus guère de modifications. Les émirs de Kaboul contrôlent encore imparfaitement le territoire. Abdur Rahman consacre son règne (1880-1901) à écraser les résistances internes. Entre 1891 et 1893 , il étend son contrôle sur le Hazaradjat. Il s'agit d'une région insoumise, largement repliée sur elle-même et dominée par de puissants chefs tribaux, que des conflits incessants divisent. Le souverain mène une série de campagnes très dures qui s'accompagnent de nombreux massacres et d'une polarisation religieuse (sunnites/chiites). Son action consacre l'Etat afghan comme une entité essentiellement sunnite et rejette les Hazaras dans la marginalité sociale, économique et politique.

Le XXe siècle sera dès lors une période difficile pour les Hazaras qui sont considérés comme des citoyens de seconde zone par l'Etat. A la veille de l'invasion soviétique, on peut distinguer quatre catégories socio-politiques parmi les élites hazaras : outre les mir (les leaders tribaux, les grands propriétaires terriens), il y a les sayyed (les descendants du Prophète, qui forment une sorte d'aristocratie religieuse largement endogame), les sheykh (les personnes ayant suivi un enseignement religieux supérieur) et les intellectuels laïques ${ }^{3}$. Les bases du pouvoir des mir sont tribales, autrement dit non reli-

Défilè du Hezbe Wahdat à l'occasion du septième anniversaire de la création du parti, Bamiyan, août 1996. Photo Iranica

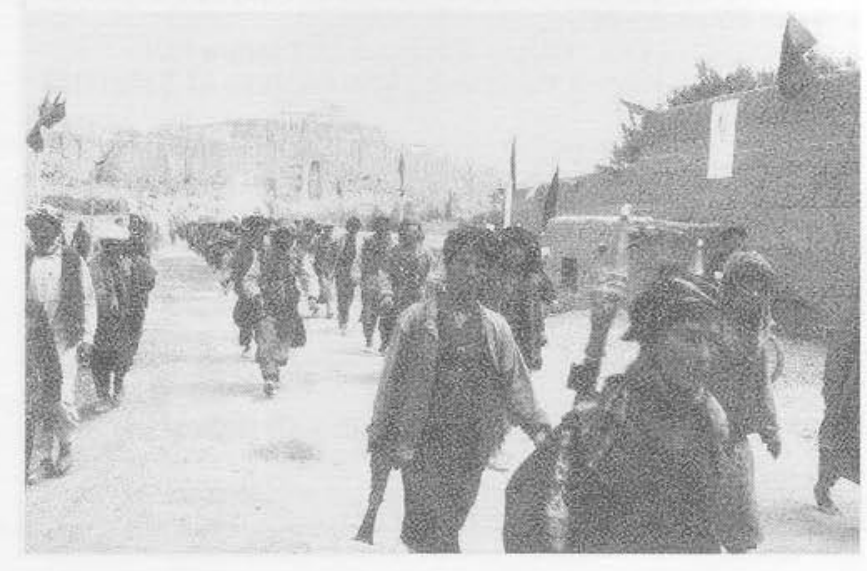




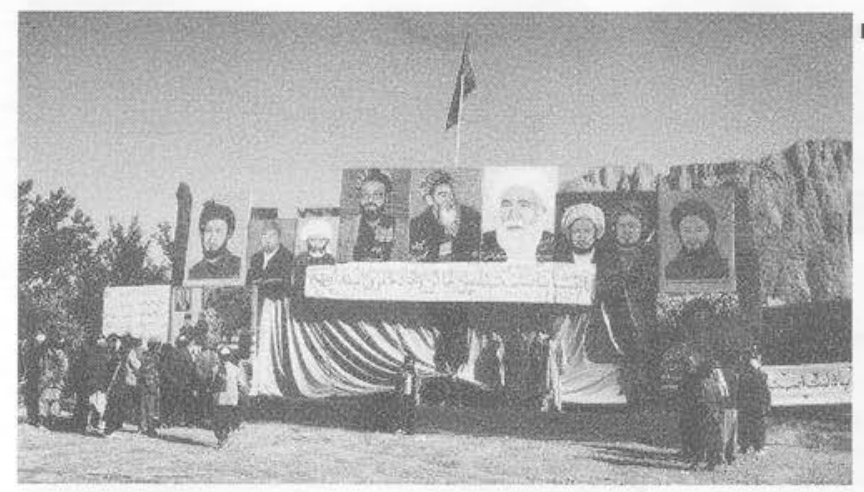

Septième anniversaire de la création du parti Hezbe Wahdat, Bamiyan, aoôt 1996. Quelques portraits de figures importantes de l'histoire des Hazaras. Photo Iranica

gieuses et locales (un groupement de villages, une vallée ou au maximum un district); les intellectuels tiennent un discours marxisant et antireligieux, ils insistent sur la nécessité d'un partage du pouvoir entre groupes ethniques et préconisent le démantèlement des inégalités sociales; quant aux sayyed, ils s'appuient sur des réseaux régionaux regroupant leurs fidèles (pouvant provenir de diverses régions du Hazaradjat); les sheykh enfin ont une sensibilité supranationale et religieuse, ils pensent le politique au niveau de l'umma (la communauté islamique des croyants) et leurs références sont orientées vers les grands centres intellectuels chiites de l'Iran et de l'Irak.

Le Hazaradjat ne constitue pas une région stratégiquement très importante et l'Armée rouge s'en désintéresse vite. La région connaît toutefois une meurtrière lutte de factions. Cette guerre intestine va causer une profonde restructuration de la société hazara. Alors que les mir dirigent la première rébellion (en 1979), très vite les leaders religieux les éliminent en s'appuyant sur le pouvoir mobilisateur de l'islam et sur les réseaux transversaux qu'ils ont su établir. Entre 1982 et 1984, les sheykh se retournent contre les sayyed et les écartent avec l'appui de l'Iran. Parmi une myriade de groupes émergent deux partis pro-iraniens, le Sâzmân-e Nasr et le Sepa-ye Pâsdârân, qui ne vont pas tarder à entrer en compétition pour la prééminence régionale. Si les luttes de factions restent une constante, les années 1980 voient la victoire d'une nouvelle classe politique, celle des jeunes khomeynistes, souvent issus de familles modestes, qui remplacent les élites traditionnelles.

\section{Les années 1990 : \\ une ethnicisation rampante}

Dans les années 1990, avec le départ des Soviétiques et l'émergence de nouveaux enjeux sur la scène nationale, les dirigeants hazaras comprennent qu'il est nécessaire de faire taire leurs antagonismes. La majorité des groupes chiites se réunissent au sein d'une nouvelle formation politique, le Hezb-e Wahdat, dont les leaders vont tenir un discours très ethnique, tout en adoptant un compromis entre les pôles laïque et religieux. Cet événement consacre la fin du processus révolutionnaire islamiste au profit d'une politique pragmatique. Les intellectuels laïques, plutôt originaires des classes moyennes et supérieures, font un retour discret à travers quelques $\mathrm{ONG}$

Dans les années qui suivent la chute du régime de Nadjibullah (1992-1994), on assiste à des changements d'alliances constants. Le Hezb-e Wahdat, par exemple, se scinde en une faction majoritaire, animée par des gens issus du Nasr (Abdul Ali Mazari, qui sera tué par les Tâlebân en mars 1995, en devient le chef incontes- té), alliée au Hezb-e Islami et à Dostum, et une faction minoritaire constituée en grande partie par le Sepa (en particulier Mohammad Akbari, l'un des leaders historiques du parti), qui finira par rejoindre le Harakat-e Islami dans le camp de Massoud.

La montée en puissance des Tâlebân à partir de la fin de 1994 (ils prennent le contrôle de Kaboul en septembre 1996 puis du centre et du nord du pays en été 1998) bouleverse une fois de plus le paysage politique de l'Afghanistan. Réunis par leur opposition aux étudiants en religion, les anciens ennemis se retrouvent dans le même camp : Massoud et le Djamiat-e Islami, les troupes de Sayyaf, le Harakat-e Islami, les diverses factions du Hezb-e Wahdat, le Djunbech-e Melli de Dostum, et même le Hezb-e Islami de Hekmatyar constituent une coalition lâche entre 1996 et 2001. Akbari finira en revanche par se rapprocher des Tâlebân.

Massoud reste solidement retranché dans le Pandjchir. Certains combattants hazaras fidèles à Mohammad Karim Khalili (qui a pris la tête du Hezb-e Wahdat après la disparition de Mazari) résistent dans le centre du pays, perdant et reprenant à plusieurs reprises le bazar de Yakaolang, alors que d'autres, sous la direction du commandant Mohammad Mohaqiq, se replient à Tcharkent (province de Balkh).

On assiste alors à une polarisation ethnique, toute relative d'ailleurs : les Pachtounes d'un côté, qui constituent la majorité des Tâlebân vs les autres groupes (les Tadjiks, les Hazaras, les Ouzbeks, mais aussi de nombreuxPachtounes des régions de Kaboul et de Djalalabad). Toutefois, la grille de lecture ethnique ne permet pas de rendre compte de la complexité des changements d'alliance entre 1992 et 2001 ni des résultats des élections présidentielles et parlementaires de 2004 et 2005. Il existe une multitude de lignes de fractures (villescampagnes ; sunnites-chiites ; Afghans établis en Occident-Afghans de l'intérieur et réfugiés au Pakistan ou en Iran ; élites de la diaspora-commandants ; royalistes-nationalistes-progressistes-islamistes...). Cette fragmentation est telle que la cohésion nationale semble difficile à atteindre, mais elle a paradoxalement eu comme effet positif d'empêcher la constitution de deux blocs antagonistes.

\section{Le processus démocratique : entre espoirs et blocages}

Les attentats du 11 septembre 2001 qui ont frappé le World Trade Center à New York et le Pentagone à Washington décident le gouvernement américain à intervenir en Afghanistan, où les Tâlebân sont accusés d'abriter Osama Ben Laden et de nombreux terroristes islamistes. La campágne de la coalition provoque rapidement la fin du régime des étudiants en religion. Les accords de Bonn, qui sont signés en décembre 2001, définissent un agenda visant à rétablir les institutions politiques afghanes. Sous l'impulsion militaire, diplomatique et financière de la communauté internationale, l'Áfghanistan a connu dès lors une évolution que personne n'aurait pu prévoir : la chute des Tâlebân et l'installation à Kaboul d'un gouvernement intérimaire, puis la tenue de deux loya djinga, l'adoption d'une nouvelle Constitution en janvier 2004, les premières élections présidentielles libres de toute l'histoire du pays en octobre de la même année, des élections législatives et enfin la constitution d'un parlement en décembre 2005. Dans la ligne des accords de Bonn, l'Afghanistan Compact (janvier-février 2006) garantit l'engagement de la communauté internationale dans les années à venir. 


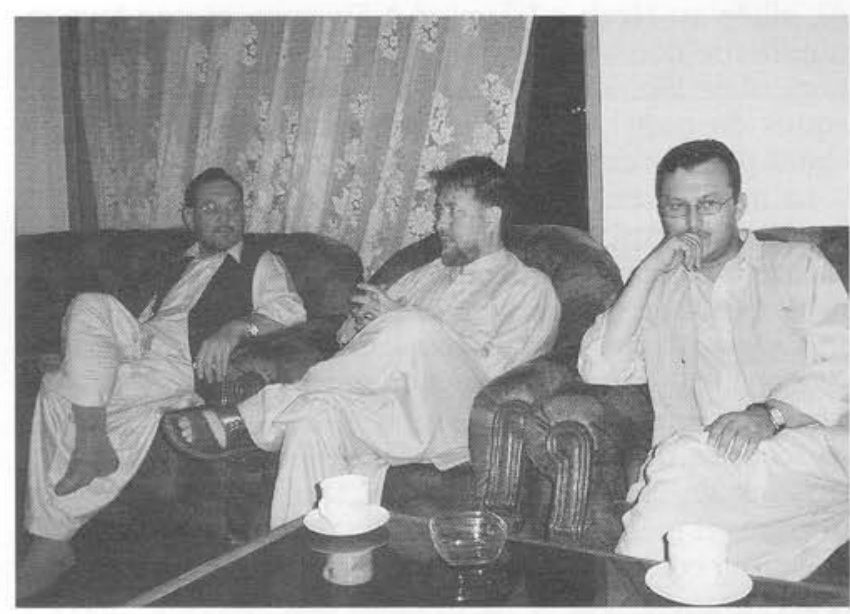

Hadji Mohammad Mohaqiq (centre) préparant les élections présidentielles, Kabou août 2004. Photo A. Monsutti

Le processus politique semble donc prendre une tournure positive et l'on serait en droit d'être optimiste pour l'avenir du pays. Toutefois, ce bilan ne doit pas faire oublier que la violence, bien loin de diminuer, connaît de nouvelles explosions. De larges secteurs du territoire national échappent toujours à l'autorité de l'Etat central et les leaders issus de la guerre conservent une grande influence. Certains se sont recyclés dans l'économie de l'opium, qui représenterait $75 \%$ de la production mondiale. La corruption généralisée gangrène l'administration et entrave la reconstruction.

Le système politique afghan n'encourage pas la constitution de partis, qui jouent pourtant un rôle essentiel en démocratie pour modérer les tensions internes. L'absence de blocs parlementaire stables conduit à l'émiettement des débats (chaque question donnant lieu à des alliances de circonstance). Cela donne en revanche de la visibilité à de fortes personnalités issues de la guerre, qui s'appuient sur leurs partisans, et donc encourage indirectement la constitution ou le renforcement de réseaux régionaux ou ethniques. Dans ces conditions et alors que l'Etat est dans l'incapacité de délivrer la plupart des services publics, le Parlement perd une grande partie de sa fonction. Plus que l'assemblée des représentants du peuple, il tend à devenir un relais de redistribution clientéliste et une arène où certains leaders charismatiques se mettent en scène.

Dans ce comexte, deux hommes qui se réclament être les héritiers d'Abdul Ali Mazari s'imposent comme les principales personnalités politiques parmi les Hazaras : Mohammad Karim Khalili et Hadji Mohammad Mohaqiq. Tous deux issus du Nasr, alliés dans les années 1980 et

\section{Les Nouvelles d'Afghanistan}

La revue LES NOUVELLES D'AFGHANISTAN est une revue trimestrielle éditée par AFRANE (Amitié Franco-Afghane). Les opinions émises dans les articles n'engagent que leurs auteurs. Titres et sous-titres sont de la responsabilité de la rédaction.

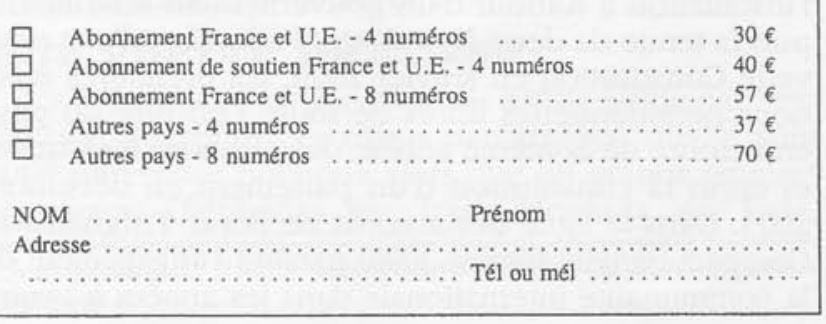

1990, ils se sont progressivement éloignés politiquement l'un de l'autre et sont entrés en compétition sans engager un conflit militaire ouvert. Alors que l'un est plutôt vu comme un diplomate par la population hazara, l'autre est un commandant dont l'un des titres de gloire est de ne s'être jamais établi à l'étranger et d'avoir longtemps résisté aux Tâlebân dans son fief du nord. Quant à Mohammad Akbari, issu du Sepa-ye Pâsdârân contrairement aux deux premiers, il effectue un nouveau virage, après s'être successivement rallié à Massoud et aux Tâlebân, et tente un improbable retour en soutenant Mohaqiq. Ce dernier se présente comme le champion de l'identité hazara. Très populaire dans de larges franges de la population hazara (parmi les ruraux comme les citadins, parmi les réfugiés et les " returnees ", mais aussi parmi les intellectuels), il est le membre du Parlement qui a obtenu le plus de voix et est l'un des principaux leaders de l'opposition au pouvoir en place. Khalili a quant à lui décidé de collaborer avec Hamed Karzaï et les forces étrangères présentes en Afghanistan. Il est ainsi devenu vice-président après les élections d'octobre $2004^{3}$. Il reçoit le soutien de nombreux notables qui cherchent à s'associer au pouvoir en place.

Les élections présidentielles et législatives ainsi que la constitution d'un Parlement n'ont pas modifié l'anthropologie politique de l'Afghanistan. Au niveau du pays dans son ensemble, comme au sein des Hazaras, on assiste ainsi à une recomposition incessante des alliances politiques ; la seule constante est l'existence de plusieurs factions opposées, toujours sujettes à des scissions internes et dont les membres ne sont jamais les mêmes. Nous retrouvons des logiques segmentaires. Lorsque l'un des groupes en présence est sur le point de s'imposer, il se scinde, alors que la partie opposée qui allait être vaincue se rallie à la frange la plus faible de ses ennemis : Phase 1 : A contre B ; Phase 2 : B est affaibli ; A se scinde en A1 et A2 ; Phase 3 : A2 et B s'allient contre A1, etc.

Mai 2006

1 Auteur de Guerres et migrations, Réseaux sociaux et stratégies économiques des Hazaras d'Afghanistan, Ed. de l'Institut d'ethnologie de Neuchatel, 2004.

2 La relation entre cousins paternels (tarburwali), qui partagent des droits sur les terres de leur grand-père, est de façon inhérente ambivalente et ambiguë ; elle se caractérise tout à la fois par la coopération et la compétition, par l'entraide et la jalousie.

3 Voir Kristian Berg Harpviken, Political Mobilization among the Hazara of Afghanistan: 1978-1992, Oslo: Department of Sociology (Rapport 9), 1996.

4 Voir mon petit texte : "Khalili et Mohaqiq : une opposition structurelle ", Afghanistan Info 56, mars 2005, p. 12-13.

\section{Afrane}

Permanence : 16, passage de la Main d'Or - 75011 Paris Tél. : (33) 01.43.55.63.50

L'association Amitié Franco-Afghane (Afrane) a été fondée au début de 1980 , en réponseà l'occupationmilitaire del'Afghanistan parles Soviétiques. Organisme d'aide humanitaire, Afrane ne souhaite qu'aider les Afghans et ne se situe dans la mouvance d'aucun parti politique. Elle soutient à présent principalement des programmes éducatifs.

\footnotetext{
$\square \quad$ Adhésion avec abonnement à la revue Les Nouvelles d'Afghanistan ................... 48 


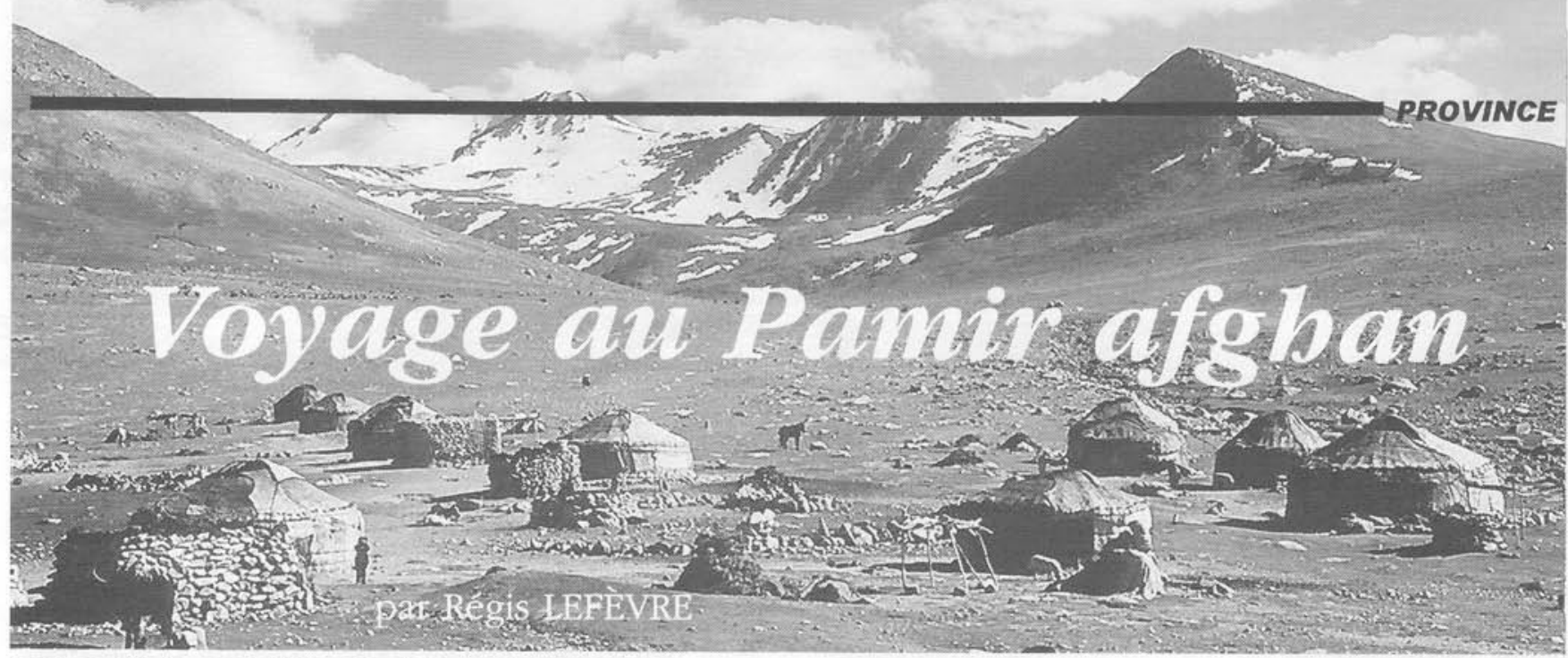

Campement de Sar-e Mo Kol (Grand Pamir). Photo R. Lefèvre

Le tourisme n'a pas encore repris ses droits en Afghanistan. Il faut encore de l'intrépidité pour sortir des sentiers (un peu) battus. Régis Lefevre est donc parti à l'aventure aux confins de la Cbine, du Tadjikistan, de l'Afghanistan et du Pakistan, dans ce qu'on appelle le Wakhan. Là-baut, les traces du contrôle gouvernemental sont imperceptibles. N'en a-t-il pas toujours été ainsi?

Pendant de terribles années, l'Afghanistan est resté pour les voyageurs une zone blanche sur la carte. C'est encore le cas de certaines de ses régions. Cet attrait de l'inconnu m'a mené durant l'été 2005 dans le Pamir' ${ }^{1}$.

J'ai toujours eu plus d'attrait pour l'histoire que pour la géographie. Mon goût pour cette dernière et un intérêt pour les cartes me sont venus par le voyage. Cette fois, une fois n'est pas coutume, tout est parti d'une carte. Cet étrange appendice, à l'extrême est de l'Afghanistan, touchant à la Chine, en a étonné plus d'un. Il fallait une réponse à ces interrogations. Las ! C'est l'histoire qui, une fois encore, donne la réponse à la géographie. Les grimoires nous apprennent que ces régions ont été données à l'Afghanistan par les empires russe et britannique à la fin du XIXème siècle, soucieux des mauvaises idées qu'auraient pu leur donner une frontière commune. Mieux valait donc qu'ils fassent pays à part. L'histoire donc.

Une fois l'explication trouvée, des questions demeurent : à quoi ressemble cette étrange excroissance, ce massif compris entre les vallées du Piandj et du Wakhan qui se rejoignent pour former l'Amou Daria? A quoi ressemble cette région des sources de l'Oxus qui constituait pour les Grecs l'extrémité est du monde connu ? Quels sont les gens qui y habitent? En définitive, la curiosité laissera une deuxième manche à la géographie.

En 2003, lors de mon premier voyage en Afghanistan, une frénésie de mouvement m'avait amené jusqu'à Qala Pandja, au premier tiers du corridor, là où se rejoignent le Piandj et le Wakhan. J'en suis parti avec la frustration de ne pouvoir fureter dans ces montagnes. Le temps m'était compté et surtout, je m'étais rendu compte qu'aller plus avant nécessitait une préparation, et qu'il n'était pas prudent de s'aventurer seul dans des endroits si peu peuplés.

L'affaire n'est pas aisée. Les témoignages sont rares. Remy Dor y est passé dans les années 70 mais je ne découvrirai son livre (en allemand) qu'à mon retour ${ }^{2}$. Les montagnards de ces mêmes années ont eu la plume paresseuse ou trop technique. De longues recherches me mettront en contact avec un ancien membre d'Acted et l'écrivain-marcheur Philippe Valery. Mais le passage remonte à 5 ou 10 ans et aucun n'a pu relier les deux Pamir. Les chemins, leurs difficultés et les temps de trajet restent inconnus. Les risques sont à considérer : nous serons jusqu'à huit jours à cheval du point sanitaire et de la piste les plus proches. Le Thuraya (téléphone satellite) fera débat mais nous conclurons qu'en cas de problème, personne ne viendra nous chercher aussi loin. L'économie en sera faite. Nous veillerons donc à la pharmacie. Et puis, nous partirons avec la certitude qu'en Orient plus qu'ailleurs, Dieu protège les voyageurs.

Nous partons à trois et trouverons à Kaboul un jeune étudiant d'Esteqlal en guise d'interprète. Voler sur Ariana est un plaisir qui se mérite. Nous aurons passé une journée entière autour des bureaux pour apprendre successivement que le vol Kaboul Faizabad n'aurait pas lieu le lendemain, l'avion ne pouvant venir de Faizabad à cause des pluies, puis que le vol était finalement maintenu mais qu'il n'y avait plus de places pour finalement obtenir des billets. Le lendemain, au bout de trois heures d'attente à l'aéroport (dont deux dans un terrain vague entouré de barbelés), on nous informe que l'avion a bien décollé et atterri mais que son mauvais état l'empêche de repartir. Un signe de la providence ? Toujours est-il que nous devons prendre la route. A Saray-e Chamali, les chauffeurs nous apprennent que nous ne coucherons pas à Pol-e Khumri : la route du Salang, refaite à neuf, relie désormais Kaboul à Kunduz en 6 heures. Partant à 13 heures, nous arriverons à la nuit tombée.

\section{Une situation économique difficile}

La piste Kunduz Faizabad est toujours aussi mauvaise. Tout au plus ne passe-t-on plus, après Taloqan, au fond de ces gorges qui marquèrent le point ultime de l'avancée des Tâlebân. Peu de ponts ont été reconstruits et seul l'embarras du choix semble expliquer que l'on n'ait pas distrait quelques pelletées des millions de tonnes de cailloux qui bordent la piste pour en reboucher les trous... La reconstruction ne paraît pas atteindre le Badakhchan. Ce n'est pas le cas des problèmes politiques : sécession de commandants locaux, incendie des locaux d'AKDN à 


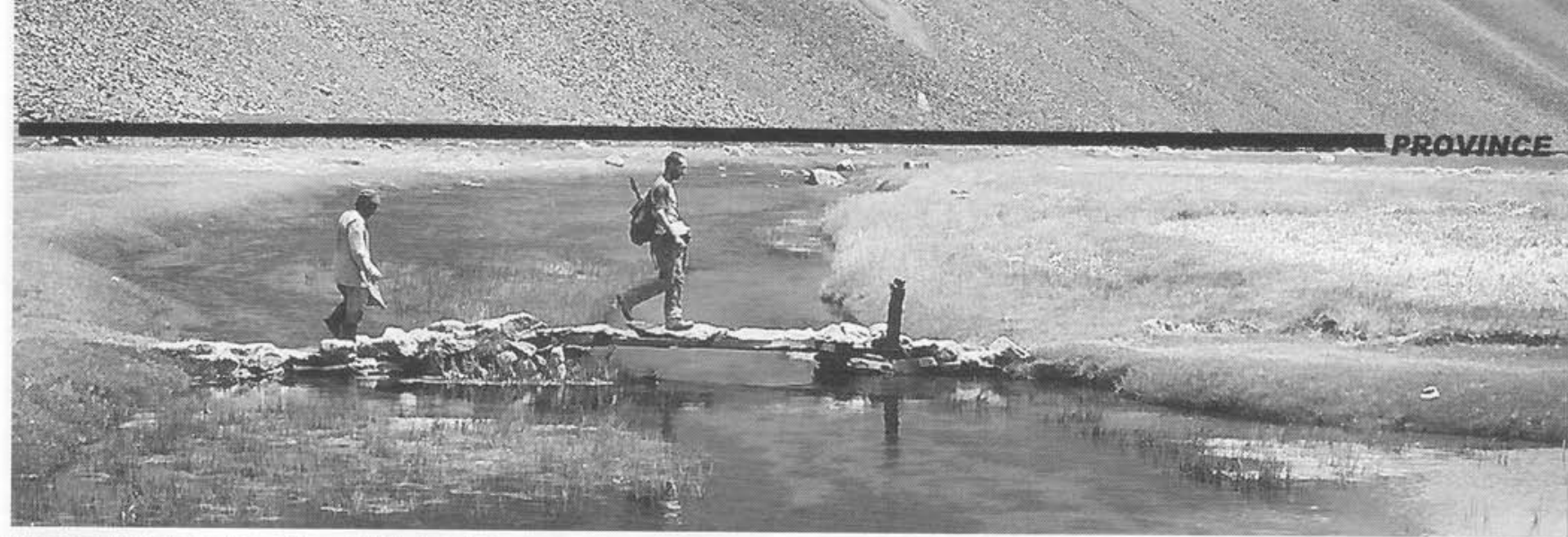

Passage d'un pont avant Sar-e Baroghil. Photo R. Lefèvre

\section{Attendre l'aide ou retrousser ses manches?}

Le commandant finit par arriver. Nos cartes et notre bonne bouille font l'affaire. L'homme est un ancien modjahed et s'embarrasse de moins de formalités ou de prudence que le wali.

Nous partons donc avec dans la poche une lettre à présenter aux points de contrôle. Le plus dur nous semble fait. Nous nous arrêtons remettre des photos de l'expédition du Nowshak (l'expédition Oxus de Mountain Wilderness) ${ }^{4}$ au chah ${ }^{5}$ de Qazi Deh. L'accueil est un peu froid. Les photos l'indiffèrent. Il nous répond qu'elles ne vont pas beaucoup aider les habitants de son village, que les montagnards du Nowshak avaient laissé des tentes, des couvertures, payé des porteurs alors que nous n'apportons rien. Il n'a pas tort, mais que fait-il, lui, chef du village, grand propriétaire terrien, homme d'affaires qui avec trois camions contrôle tout le trafic de marchandises de la vallée, que fait-il pour aider les habitants de sa vallée? Au fur et à mesure de mes voyages en Afghanistan, j'ai de plus en plus l'impression que l'attente de l'aide extérieure est souvent un prétexte pour ne pas agir. Il sera facile de faire porter le chapeau des problèmes à l'étranger. "Ne pille déjà til pas l'argent dû à l'Afghanistan ?" Qui n'a déjà entendu ces propos?

Khandud est un village qui s'enorgueillit de deux boutiques et d'une clinique. C'est le lieu que choisit notre chauffeur pour nous annoncer qu'il n'a plus assez d'essence pour aller plus loin. Il est parti les jerrycans vides alors que passé Ichkachim, il n'y a plus de pompe à essence. Ce n'est sans doute pas un hasard alors qu'il n'a cessé de se renseigner à Ichkachim. Peur de casser son véhicule? Toujours est-il qu'avec son départ, nous nous retrouvons à pied, mais que surtout nos chances d'avoir un véhicule qui vienne nous rechercher s'évanouissent. Finalement, nous louons la jeep du chef de poste et négocions au prix fort les derniers litres d'essence stockés chez les particuliers du village. Tout le monde nous assure que nous trouverons aussi de l'essence à Qala Pandja. La vieille jeep n'a ni freins ni démarreur et chaque passage de gué est un pile ou face : pourvu qu'elle ne cale pas. L'aide du chauffeur court dans l'eau à chaque rivière pour lui indiquer le passage.

Nous arrivons à Qala Pandja, point ultime de mon périple d'il y a deux ans. Chah Ismaël, un homme chaleureux, nous reçoit. Une discussion intéressante, reposant sur des questionnements réciproques, s'engage. Les habitants du Wakhan, les Wakhis sont ismaéliens. Le Chah en est le leader religieux. Ce n'est pas un hasard de trouver ici des ismaéliens : ces "infidèles " pour de nombreux sunnites ont été partout repoussés sur les plus mauvaises terres, les seules que nul ne leur disputait. La situation de ces populations est désastreuse : déficit sanitaire complet, carences alimentaires, $40 \%$ de mortalité infantile avant 5 ans. Ici, un homme ne mentionnera jamais la mort d'un enfant de moins de deux ans ; il faut poser la question aux femmes pour prendre conscience du problème. C'est ce que m'a appris il y a deux ans Alex Duncan (ONG O.R.A), médecin anglais qui vit dans la région, totalement isolé avec sa femme et un enfant en bas âge. Sa femme était enceinte et allait bientôt accoucher en Angleterre. Je me souviens de la réponse qu'il m'avait faite lorsque je m'étais étonné de sa décision de revenir dans le Wakhan avec un nourrisson: " mon action est tournée vers les mères et les enfants. Quelle serait ma crédibilité si je ne revenais pas avec mon bébé ? ". Cet été, Alex est absent, parti en Angleterre pour la naissance de son troisième enfant mais il reviendra.

Les 200 litres d'essence que nous devions trouver à Pandja se sont évaporés, utilisés l'an dernier dans un générateur. Le peu que nous trouvons ne nous suffira pas à aller jusqu'à Sarhad (la jeep consomme 50 litres aux $100 \mathrm{~km}$ ). Nous partons au petit matin. La nuit, le gel retient l'eau et le débit des rivières est plus faible à l'aube. Le départ est un peu houleux : la jeep aux freins défaillants renverse une barrière gardée par des soldats qui nous braquent, et puis tout finit par s'arranger en riant. Nous disputons toutefois notre laissez passer aux soldats analphabètes qui tentent de le garder, de peur que notre passage leur soit reproché. Moins d'une heure plus tard, nous devons nous arrêter : trop d'eau, la jeep ne peut plus passer; il nous faut continuer à pied et notre trajet se rallonge de trois jours de marche pour atteindre Sarhad. La jeep et ses litres d'essence désormais inutiles repart en s'engageant à venir nous chercher dans trois semaines, Inch'allah. Sera-t-elle au rendez vous?

\section{Un contact âpre}

De l'autre coté de la rivière, des bergers nous louent des ânes jusqu'au soir (nous portons $30 \mathrm{~kg}$ de nourri-

" II nous faut continuer à pied et notre trajet se rallonge de trois jours de marche pour atteindre Sarhad „. Photo R. Lefèvre

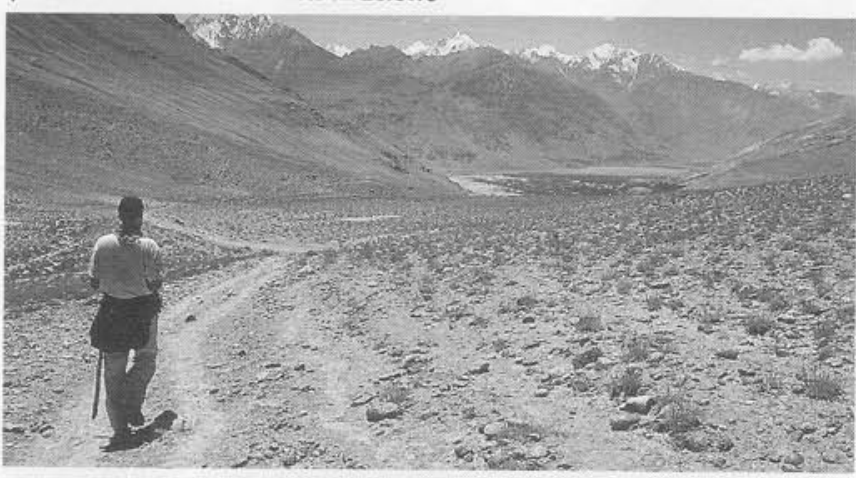




\section{PROVINCE}

ture). Dans les faits, ils s'arrêtent une heure et demie plus tard au village suivant. Le premier contact avec les Wakhis est plutôt rude : ils nous expliquent qu'ils ne peuvent nous louer des bêtes que jusqu'au prochain village (à moins de trois heures !) et qu'il nous en coûtera 20 dollars par âne. Je ne m'attendais pas à une telle demande dans un endroit où aucun étranger ne passe. La discussion est âpre et il s'en faut de peu que nous finissions par jeter à l'eau provisions et bagages pour continuer sans animaux. On ne loue pas un âne 20 dollars par jour dans un pays où un instituteur en gagne 60 par mois. Nous finissons par trouver un point d'entente mais partons sans échanger une poignée de main. La même scène se reproduira à chaque village de la vallée, parfois deux fois par jour. Chacun voudra prélever sa taxe et nous perdrons des heures à négocier. Très décevant mais, après tout, qui sommes- nous? Des privilégiés ayant eu les moyens d'arriver jusqu'ici, dans des villages où nul n'a les moyens de mettre du sucre dans le thé ? Dans ce monde clos où la vie est si difficile, tout passage est une occasion de gagner de l'argent, d'améliorer le quotidien, en recourant à de menues escroqueries. Certes, on nous accueillera toujours pour la nuit, acceptera de cuire notre riz, nous offrira thé et pain mais quand, en remerciement, nous achèterons un poulet au prix exorbitant ici du bazar de Kaboul, on nous servira un coq dur comme du bois.

Le terme de corridor du Wakhan n'est pas usurpé la vallée parfois n'excède pas quelques dizaines de mètres de large et les montagnes grimpent de chaque coté au dessus de 6000 mètres. Les terres cultivables sont rares et les torrents, qui déboulent des glaciers comme les éboulements, les disputent aux hommes. A 3000 mètres, le blé qui y pousse est bien chiche. Quelques fèves font office de seuls légumes. Aucun fruit ne pousse dans cette vallée. L'hiver dure six mois et la soudure creuse chaque année ventres et joues. Le bois est rare pour construire, se chauffer ou cuire les aliments. Le dénuement est parfois criant comme dans cette masure isolée où nous nous arrêtons faire une pause : une marmite, un peu de farine et de thé, une théière, deux bols ; les habitants du lieu n'ont rien d'autre, à part les vêtements qu'ils portent. Comment les hommes font-ils pour s'accrocher ici? Les conditions de vie sont dures. Les Wakhis se plaignent de leur isolement, du manque de routes, de ponts mais que font-ils pour tenter de les améliorer? Il suffirait de peu pour rendre cette piste plate carrossable. Chacun ne voit pas plus loin que son village.

Nous sommes surpris en chemin de constater que des écoles sont présentes dans toute la vallée, parfois

La pause. Aref, notre interprète (à gauche), Golmahmad et son jeune frère, nos guides kirghizes. Photo J. Dufour

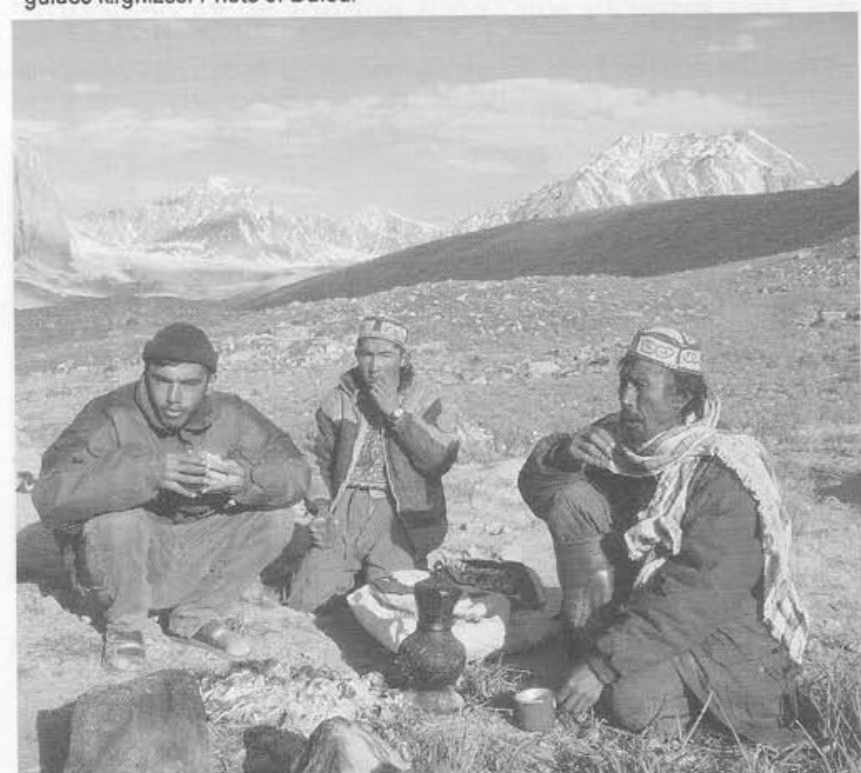

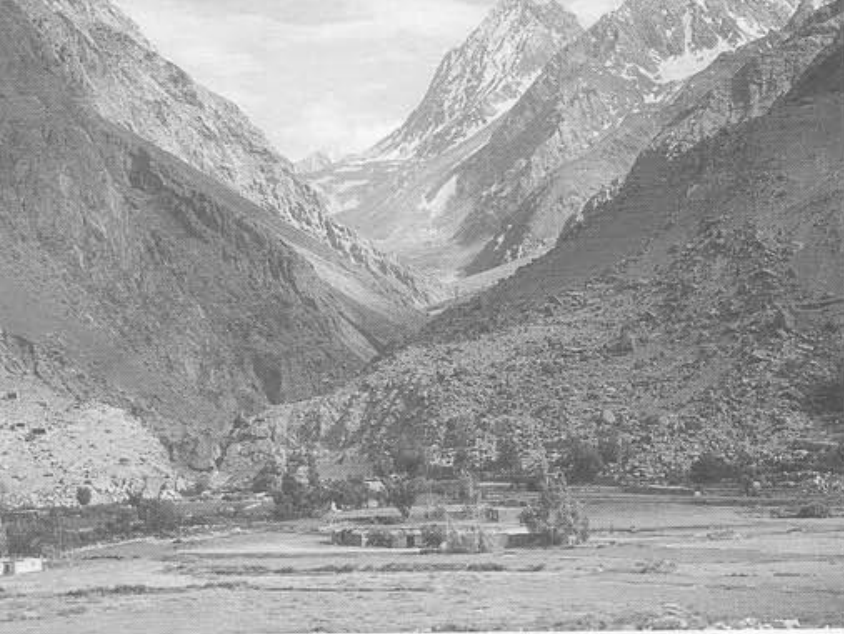

Vallée du Wakhan. Vue sur les hauts sommets de l'Hindou-Kouch qui la séparent du Pakistan. Photo R. Lefèvre

encore sous tente Unicef. AKDN (l'ONG de l'Aga Khan est la seule ONG à soutenir la région, au travers d'aide à la construction de logements, de soutien d'écoles ou de projets de reboisements.

Au terme de trois jours de marche, entrecoupés de passages difficiles de rivières, nous arrivons à Sarhad-e Baroghil. C'est le bout de la vallée du Wakhan, fermée par des gorges. Vers le sud, le col de Baroghil mène au Pakistan. L'accès en est aisé mais la frontière est fermée, compliquant considérablement la vie des habitants : tout doit venir d'Ichkachim alors que le Pakistan est si proche. A Sarhad, se trouve une poignée de soldats. C'est le dernier signe de la présence de l'Etat afghan : nous n'en croiserons pas d'autre dans les deux semaines à venir.

\section{Le petit Pamir}

Nous attendons deux jours des animaux de bât. Au dernier moment les trois chevaux promis se transforment en deux juments et un âne. Nous partons enfin sans trop savoir jusqu'où nous pourrons aller : le temps nous est compté et le chemin incertain, fonction du niveau des eaux. Les guides restent évasifs sur la durée des différents trajets : 3 jours, 6 jours ? Notre route, déjà éprouvante physiquement, sera émaillée de conflits avec les guides qui tentent de nous ralentir pour être payés plus de jours, prétextant de l'état de leurs animaux.

La vallée du Wakhan était très plate. A présent difficultés et cols se succèdent : Dalriz et ses pierriers 4250 mètres, Ghamundi 4895 mètres (glacier et éboulis), Akbilis : 4600 mètres. En 4 jours, nous avalerons plus de 5000 mètres de dénivelé total, à plus de 4000 mètres d'altitude, à raison de plus de sept heures de marche par jour. Eprouvant, mais les chemins plus faciles pour atteindre le petit Pamir passent au nord, par le Tadjikistan dont la frontière est fermée même pour les locaux. La

Le village de Wakhi. Les terres cultivables sont rares et les éboulements les disputent aux hommes. Photo R. Lefèvre

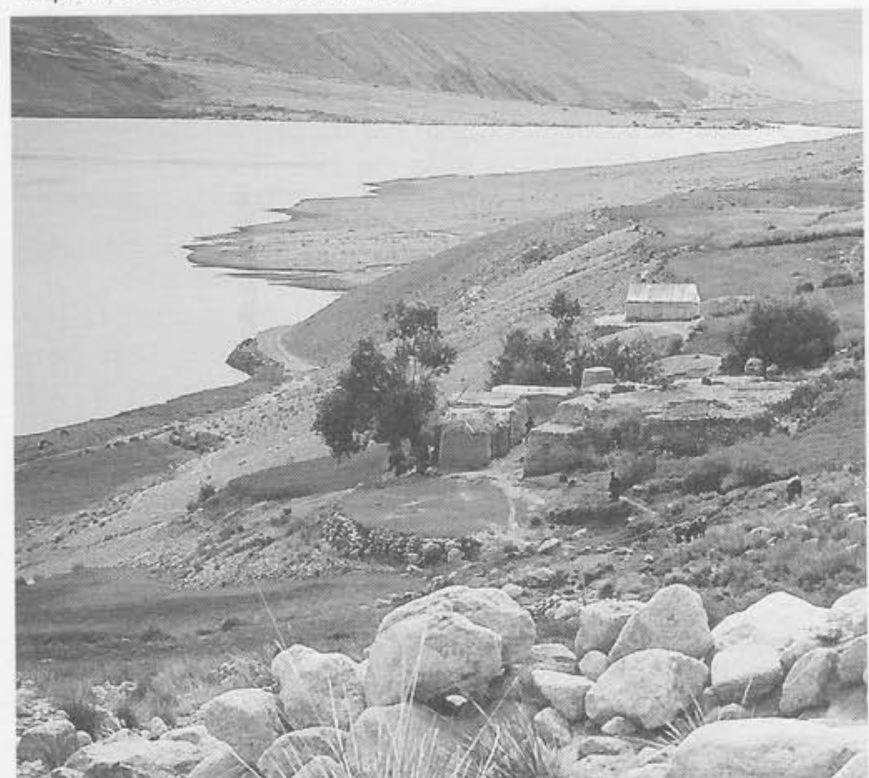




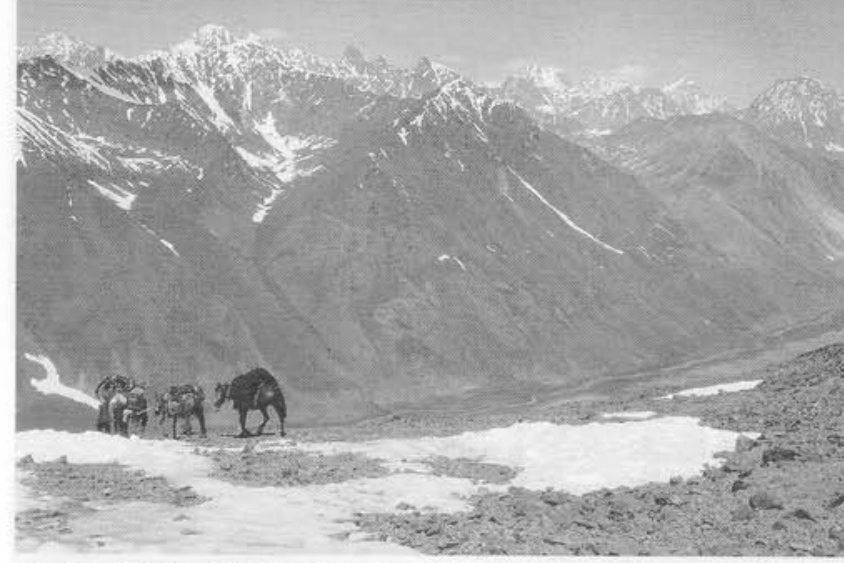

Passage du col de Karabel. Photo J. Dufour

frontière chinoise, dont nous ne sommes qu'à trois jours de marche, est fermée hermétiquement par l'armée chinoise. Le petit Pamir fait partie des confins. Depuis l'Afghanistan, nul ne peut l'atteindre sans passer ces cols dangereux où les animaux peinent à trouver leur chemin dans des chaos de pierres, ou risquent de se rompre les pattes sur la glace. L'histoire, la politique autant que la géographie ont fait que ces populations sont parmi les plus isolées qui soient.

Le petit Pamir est habité par des nomades Kirghizes (turcophones), vivant de leurs troupeaux. Bien qu'isolés, leur économie repose sur les échanges. Les commerçants viennent d'Afghanistan leur apporter riz, sucre, huile, thé et vêtements et repartent avec des moutons. L'arrêt des échanges pendant la guerre a failli les anéantir. Rien ne pousse au petit Pamir. Si les commerçants n'arrivent plus, plus moyen de se procurer les denrées nécessaires pour passer l'hiver. De fait, les Kirghizes s'organisent pour maintenir les sentiers et les ponts et bâtir des abris pour les voyageurs. Quel contraste avec les Wakhis! Les échanges leur sont vitaux. Vitaux et parfois mortels car l'opium, marchandise de peu de poids et de grand prix, arrive dans le Pamir. Un kilogramme s'y échange contre trois beaux moutons. La consommation est forte, nos guides en fument ou l'ingèrent. Le chef du village de Bourgitiar y a sombré et en fumerait plusieurs dizaines de kilogrammes par an, décimant ainsi des troupeaux.

L'isolement politique et géographique du petit Pamir explique la présence des Kirghizes. Vivre toute l'année dans des vallées à plus de 4000 mètres, où les hivers sont atroces pour les hommes et les bêtes, n'est pas habituel chez les Kirghizes. Montant rarement aussi haut, ils redescendent l'hiver dans des vallées plus accueillantes. La fermeture des frontières après la révolution bolchevique puis la prise du pouvoir par les communistes en Chine en ont décidé autrement. De nombreux Kirghizes, fuyant la collectivisation des troupeaux, ont fini par s'installer dans les Pamir afghans. Une grande partie a fui au Pakistan dès l'invasion soviétique. Ils ont été finalement implantés en Turquie. Entre l'exil et les années de guerre, le nombre des Kirghizes du Pamir a été divisé par 4 depuis les années 70.

Aujourd'hui, les Kirghizes se plaignent de leur isolement, d'être ignorés du pouvoir afghan : pas d'école, de centre de soins ni même de carte d'identité, encore moins de passeports qui leur permettraient d'aller au Pakistan, d'y vendre leurs moutons. Ils ont pu voter aux présidentielles mais pas aux législatives. Le vote n'a pas été organisé dans le Pamir. Qui se soucie des Kirghizes du Pamir ? Leur isolement leur pèse mais ils n'abandonneraient pas leur mode de vie, garant de leur liberté. Ils n'abandonneront pas leur île au milieu des montagnes. Leur mode de vie leur procure une certaine aisance par rapport aux Wakhis : l'herbe est chiche dans ces pâturages mais l'espace est grand et peut porter les troupeaux. L'hiver est l'ennemi, quand le gel ou de fortes chutes de neige empêchent les bêtes de gratter à la recherche d'un peu d'herbe. La faim et le froid tuent en moyenne chaque année un quart du troupeau. Même les yacks peuvent succomber au froid. Un mauvais hiver peut emporter la moitié des moutons. Rien n'est acquis dans le Pamir. Les hommes passent l'hiver dans des yourtes qu'ils essaient de chauffer tant bien que mal avec de la bouse de yack (il n'y a pas de bois à cette altitude). En plein mois de juillet, à 4000 mètres, il gèle tous les soirs et un maigre $3^{\circ}$ nous saisira au réveil dans la yourte. Alors, quelle température en plein hiver? Tous les Kirghizes souffrent de problèmes de vue : la fumée âcre des bouses, les carences, le soleil en altitude, la réverbération sur la neige?

\section{L'hospitalité kirghize}

Nous venons d'apprendre que rejoindre notre point de départ en passant par le Grand Pamir et en suivant le Piandj était possible, à condition de ne pas perdre trop de temps. Il nous faut donc partir. De nouveau les cols : Akbilis, Ghamundi, puis Karabel (4820) et Chowr (4890). Dans le Pamir, la géographie sait s'imposer. Il faut quatre jours d'une marche éprouvante pour rejoindre le grand Pamir et de peu : à peine avons nous passé Chowr que la montagne se voile et qu'une tempête de neige s'abat sur le col. A quelques heures près, nous aurions dû rebrousser chemin et renoncer au grand Pamir. Nous rejoignons la communauté kirghize du grand Pamir : 500 à 600 personnes dont le chef réside au pied du lac Zor Kol, à la frontière tadjike

Pas d'introduction, de surprise. A peine entrons-nous dans le campement que nous sommes dirigés vers la yourte réservée aux hôtes de passage. A peine sommesnous assis qu'arrivent thé, pain et yảourt à volonté. Le chef se montrera plus tard. La yourte lui appartient ; il lui incombe d'assurer gîte et couvert aux voyageurs. La discussion s'engage : d'où venons-nous, qui sommesnous ? Le pourquoi n'est jamais à l'ordre du jour. Les nomades ne se soucient pas du mouvement; il leur est naturel. Ni surprise, ni suspicion : celui qui passe est le bienvenu et les visiteurs sont rares. Avons-nous eu beaucoup de prédécesseurs? Beaucoup, nous répond le chef : deux l'an dernier, personne il y a deux ans, un il y a trois ans et aucun auparavant.

Le chef est déjà sorti du Pamir, est allé à Kaboul pour présenter des doléances (sans grand espoir) à Karzai. Il suffirait de peu pour améliorer leur vie : pouvoir se rendre au Tadjikistan ; utiliser la route qui, coté tadjik, longe la frontière, pour pouvoir se rendre en Afghanistan, en faire venir des marchandises et y acheminer des moutons ; pouvoir laisser paître les troupeaux de l'autre coté l'hiver (il neige moins coté tadjik). La frontière est close et étroitement surveillée. Qui se soucie d'améliorer le sort des Kirghizes du Pamir? Nous proposons la nourriture que nous avons amenée. " Gardez ce riz pour chez les Wakhis ". L'accepter serait contrevenir aux lois de l'hospitalité. Les Kirghizes sont volontiers condescendants envers les Wakhis. Les deux populations se côtoient peu. Les Wakhis mènent leurs troupeaux l'été dans le grand Pamir mais dans des vallées bien délimitées. Nous tentons de faire goûter à nos hôtes des soupes en sachet mais le goût leur déplaît (pour notre part, nous ne goûterons guère le riz au lait à l'huile qu'on nous offrira). Ils ne connaissent ni fruits ni légumes. A l'ordinaire : riz, pain, pâtes, lait, yaourt et crème et un peu de viande. 


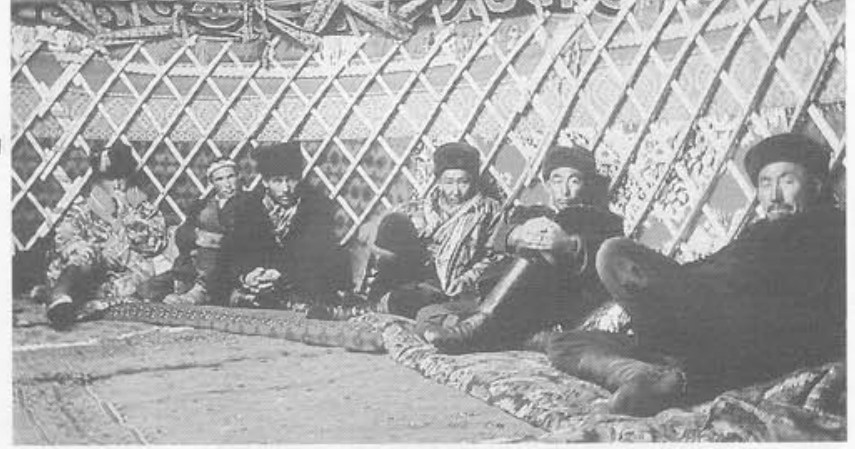

Campement de Sar-e Mo Kol. Yourte réservée aux hôtes. Photo R. Lefèvre

Travaux de bourrellerie. Photo R. Lefèvre
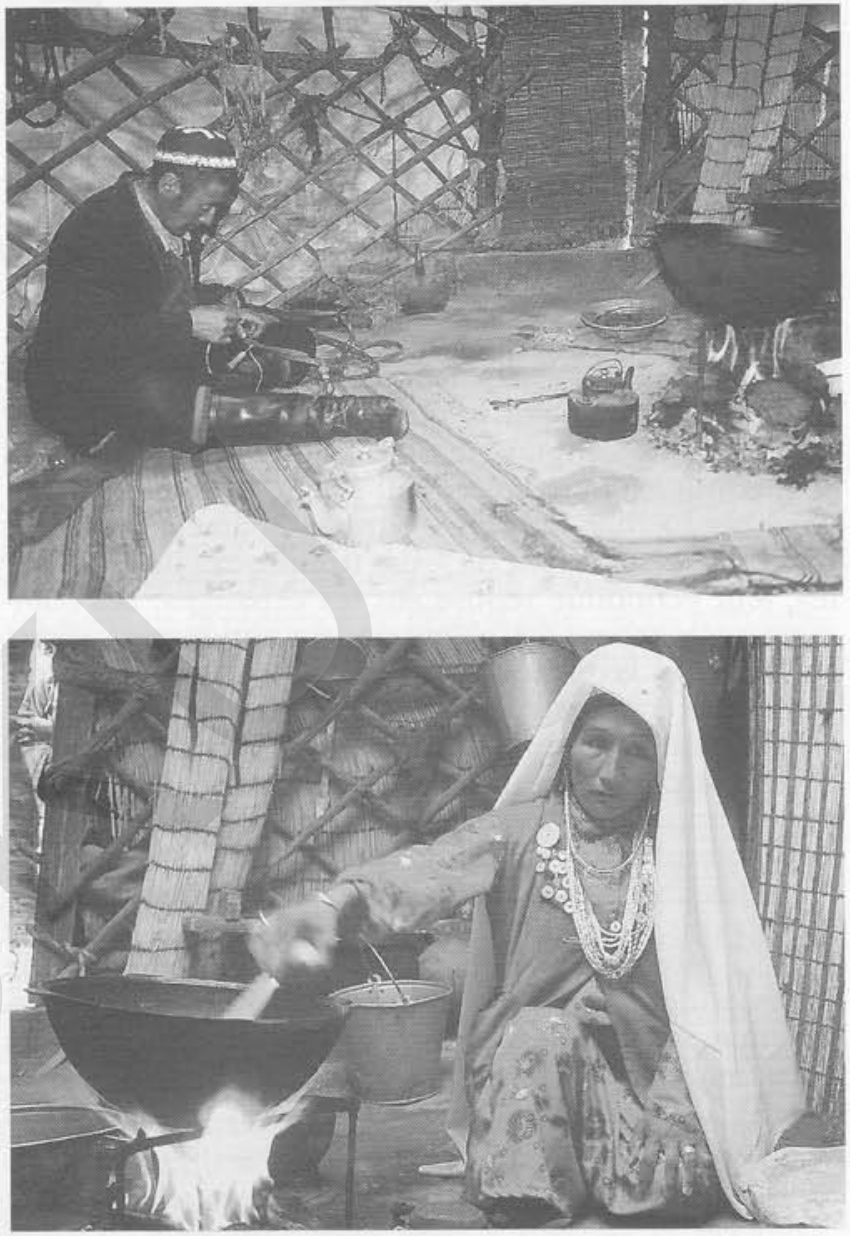

" Juste un feu de bouses à méme le sol qui enfume la tente ». Photo R. Lefèvre

Fileuse kirghize. Photo R. Lefèvre

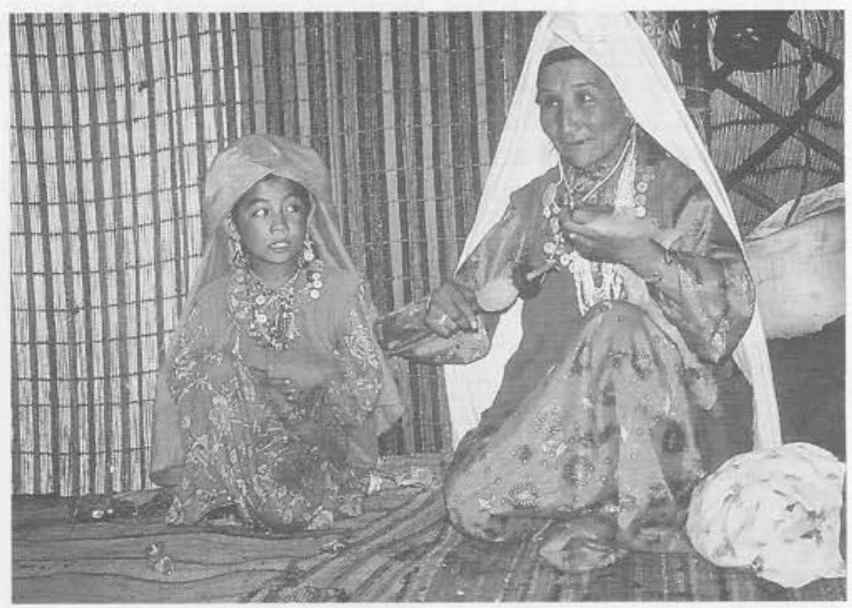

plus haut sommet d'Afghanistan. IMW a lancé des programmes de formation à la montagne en Afghanistan. Voir www.mountainwilderness.org. M.Wilderness est en train d'organiser un trek dans le Pamir Afghan.

5 Chef de village de Qazi Deh 


\title{
Quelque part dans Paris... des oiseaux sans nid
}

\author{
par Julie GOISLARD
}

\begin{abstract}
Trois ans après la fermeture du centre de Sangatte, des centaines d'exilés afghans sont livrés à eux-mêmes dans les rues de la capitale, sans toit ...et sans avenir.
\end{abstract}

Ils sont là mais personne ne les voit plus.

Ils sont là mais leurs silhouettes, juvéniles pour certains, tassées pour d'autres, ont fini par se fondre dans ce qui est devenu le paysage monotone de leur exil, le point de chute d'un long parcours à travers l'Europe. Là, dans un square municipal près de la Gare de l'Est, ils passent leurs journées ensemble en attendant. En attendant quoi ? Ils ne le savent pas vraiment, trop conscients qu'ils sont de la réponse que délivrera l'OFPRA à ceux qui y ont déposé une demande d'asile. Le statut de réfugié, ils en rêvent sans tropy croire de peur d'être déçus unefois de plus. Auparavant, ces Afghans-là avaient encore des illusions sur cette vieille Europe et ses capitales illuminées dont les télévisions leur renvoyaient les images.

Mais ici, les lumières ne sont pour eux que mirages. Ici, ils sont devenus des " sans" : sans papiers, sans patrie, sans famille, sans abris quand la météo se joint aux autres éléments et s'acharne contre eux. Alors, c'est la pluie qui s'infiltre sous les couches de vêtements trop minces, c'est le vent qui ne porte aucune promesse. Pour les jours de grand froid, Médecins du Monde.leur a distribué des tentes. Certaines nuits d'hiver, ils s'y sont parfois entassés à plusieurs quand les foyers ne pouvaient plus remplir leur fonction d'accueil. Alors les plus vaillants ont dormi sous un pont ou dans les cabines téléphoniques du quartier.

\section{Passeurs \\ vendeurs de rêves}

Les plus jeunes paraissent vieux d'avoir traversé tant de pays, d'avoir déjoué tant d'obstacles. Leur physique n'est plus en adéquation avec leur âge. Pendant la journée, ils jouent parfois au football. Ils parviennent encore à rire de leur condition et l'on peine à savoir ce que ce rire contient d'efforts. Les plus vieux ont appris à ravaler leur fierté de s'être fait flouer par les passeurs, cette mafia qui se repaît des guerres modernes laissant des Etats exsangues. Les passeurs, ils leur ont vendu un rêve, celui d'une Europe qui ne serait pas une citadelle imprenable, celui d'un continent qui les accueillerait les bras grand ouverts, celui d'une France patrie des Droits de l'Homme.

Ce voyage, ils l'ont payé cher : 500 dollars par personne pour une traversée vers la Grèce sur une embar- cation de fortune surchargée, 3500 pour franchir les montagnes turques à pied. Mais le coût du périple n'est pas seulement financier, il est aussi humain. A bord de leurs navires de misère, ils ont ramé la peur au ventre, en s'encourageant sans cesse. " On y arrivera " se répétaient-ils. Parfois, la mer est agitée et quelqu'un tombe à l'eau. Ils retiennent un père dont l'enfant s'apprête à périr dans les eaux internationales. Ils ont appris de nouvelles lois : sauver sa peau quitte à perdre un peu de son humanité. Ils n'ont pas le choix : c'est ça ou accroître le nombre des tombes d'Afghans morts noyés, épuisés et enterrés dans un cimetière improvisé le long des côtes italiennes. Quand ils parviennent à accoster sains et saufs, ils sont humiliés par la police aux frontières qui leur crie "Dehors les fous ! Retournez chez vous!". Mais ce chez eux, ils l'ont fui.

\section{Condamnés à l'errance}

Histoires fictives destinées aux agents de l'OFPRA ou départ précipité de leur foyer par crainte de menaces réelles, leur pays natal est désormais loin. Parmi eux, certains ont quitté l'Afghanistan depuis deux ans, deux années de vagabondage à travers des itinéraires balisés. Dans leurs bouches, ce sont les mêmes noms de villes qui reviennent, les mêmes contrées : Iran, Turquie, la Grèce - qu'ils dénoncent unanimement comme le pays qui les a le plus maltraités -, l'Italie et enfin la France. Paris. Un square.

On leur demande ce qu'ils disent à leurs familles restées à Ghazni, à Kaboul, dans l'Helmand, à Zaboul. Ce qu'ils livrent de leur vie de clandestins. Certains admettent mentir, leur cacher la vérité pour ne pas les inquiéter ni décevoir ceux qui ont parfois contribué financièrement au voyage. Ils présentent la France sous son meilleur jour pour ne pas les offenser. Finalement - disent-ils- ce qu'ils subissent ici n'est rien comparé au quotidien de leurs familles là-bas, si loin. Alors, ils feignent de s'accommoder de cette vie dans ce parc, des bus qui les ramassent à 19 heures (21 heures quand les premiers sont pleins) pour les conduire dans un centre où ils passent la nuit. "Nous ne sommes pas prioritaires. 
Les bus ramassent d'abord les vieux, les malades, les clochards ; les Afghans viennent en dernier " rigole l'un d'eux.

\section{En finir avec l'incertitude}

Ils s'étonnent encore de voir dans les rues de Paris des passants d'origine africaine avec cette couleur de peau qu'ils ne connaissaient pas, ils rient des jupes des femmes dévoilant leurs jambes, de cette peau offerte à leurs yeux.

Mais quand donner le change devient trop pénible, fatigués ils livrent simplement ce souhait : "Tout ce qu'on demande, c'est connaître notre destin, en finir avec l'incertitude ". Celui qui a pris la parole est en France depuis trois ans. Sa demande d'asile auprès de l'OFPRA a reçu un avis défavorable au bout de quatre mois sans entretien préalable. Il a déposé un recours dont la réponse a mis cette fois-ci huit mois à lui parvenir : un refus. Pendant ce temps, il a pris des cours de français qu'il maîtrise correctement. Maintenant, il ne sait plus quoi faire...

Ces silhouettes errant dans Paris font toutes le même constat : la police française les laisse jusqu'à présent relativement tranquilles, fermant les yeux sur leur présence mais jusqu'à quand cette indulgence? Et qui viendra ôter les pansements symboliques pour apporter des vrais remèdes à des maux réels ? Ils sont des vagabonds modernes ballottés de pays en pays sur un continent qui ne veut pas d'eux, établissant leur refuge dans celui qui paraîtra tolérer leur présence illégale.

Djalil ${ }^{1}$ a, dit-il, " l'impression d'être un oiseau sans nid ". Dans les jours à venir, il tentera une traversée de plus. Le voyage de trop? Avec beaucoup de chance, la mer devrait cette fois-ci le mener en Irlande. Son nouvel eldorado.

\section{Kbaled Hosseini L'itinéraire d'un romancier afghan}

par Jack CHABOUD

\section{Les Afghans doivent de très grands malbeurs à leurs envabisseurs soviétiques et à leurs intégristes formatés au Pakistan ; mais ils leur "doivent " aussi - du fait de l'exil - la découverte d'une forme de littérature inusitée dans leur pays : le roman.}

Le roman est une forme littéraire qui est née et s'est développée principalement en Europe et dans les pays qu'elle a colonisés. Après les Etats-Unis, l'Amérique du sud a ainsi fourni le plus flamboyant réservoir de romanciers depuis la deuxième moitié du XXe siècle. Plus récemment, les auteurs africains, indiens, ou extrême-orientaux, qui s'exprimaient traditionnellement par le conte, le récit épique ou la poésie, sont devenus des romanciers dans la forme occidentale, souvent dans celle du pays qui les a colonisés, ou de la terre d'accueil où ils se sont réfugiés. Jamais colonisé, l'Afghanistan vient de s'éveiller au roman, forme pressentie par Bahoddin Madjrouh, puis abordée par ses exilés comme Atiq Rahimi ${ }^{1}$ qui s'inscrit dans une forme littéraire très épurée, à la française, Assem $\mathrm{Akram}^{2}$ qui a subi l'influence des deux côtés de l'Atlantique, et Khaled Hosseini ${ }^{3}$ qui a suivi une piste américaine, où la finesse d'écriture et de construction romanesque n'exclut pas la passion de l'Histoire et la séduction des histoires. Ainsi sont nés Les cerfs-volants de Kaboul, roman de trahison, de remords et de repentir, aventure haletante, ode au souvenir, à la nostalgie, à l'amitié, plainte du déracinement, chant d'amour à son pays et à son père.

L'histoire de ce roman, c'est d'abord celle de Khaled, né à Kaboul en 1965, aîné de cinq enfants, fils d'un diplomate et d'une mère professeur de dari et d'histoire. En 1975, son père, Nasser Hosseini, quitta Téhéran pour Paris comme deuxième secrétaire d'une ambassade dirigée par Mohamed Akram. En 1976, la famille Hosseini habitait à deux portes de mon appartement, à Courbevoie, et nous devînmes amis. Un jour, Khaled me fit lire le texte d'une nouvelle, et je l'assurai sincèrement de la réelle qualité de son récit. Après le sanglant coup d'Etat communiste de 1978 et l'entrée des Soviétiques à Kaboul en décembre 1979 , Nasser et sa famille obtinrent l'asile politique aux Etats-Unis à l'automne de 1980 . Nous ne devions plus nous revoir, sans jamais cesser de correspondre, par courrier puis courriel.

Seize ans après son départ, je reçus de Khaled une nouvelle fantastique en anglais et, comme pour Assem Akram, je lui suggérai d'écrire un roman pour une de mes collections de textes pour la jeunesse. Le ver était dans le fruit. 


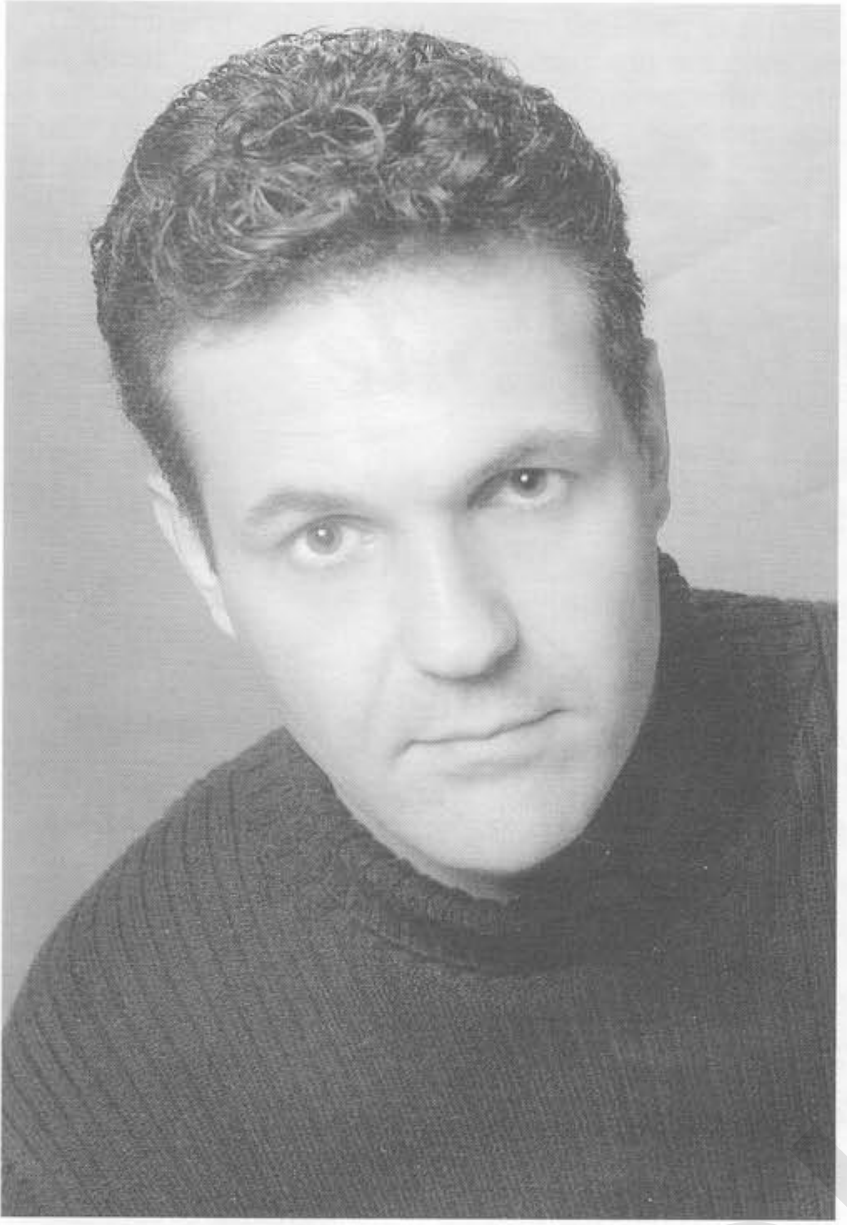

Khaled Hosseini @ Image Arts Etc

Installé avec sa famille à San Jose, sur la côte Ouest des Etats-Unis, Khaled, sa sœur et ses trois frères firent leurs études en travaillant pour les financer. Khaled suivit les cours de l'université Santa Clara et reçut son diplôme de médecin généraliste de l'école de médecine de San Diego en 1993, avant d'exercer dès 1996 dans un hôpital de San José. Marié à Roya une juriste d'origine afghane, avec qui il a eu deux enfants, Farah et Haris, Khaled portait en lui un désir d'écrire, assez fort pour le pousser à aller se perfectionner dans une de ces creative writing schools d'où sortent régulièrement des auteurs américains.

Malgré sa famille et sa charge de travail, Les cerfs-volants de Kaboul commencèrent bientôt à voler dans sa mémoire. Il entreprit alors de se lever chaque nuit pendant deux ans, avant de prendre son service, pour faire naître et vivre Amir, Hassan et Sohrab, personnages de son roman qui ne le quittèrent plus.

Le livre, paru en anglais sous le titre de The kite runner, a connu un succès étonnant aux Etats-Unis, où il a été le numéro un de la liste des best-sellers du New York Times pendant un an et fait l'objet d'un véritable culte. Le roman a été traduit dans une trentaine de langues.

Je n'ai revu Khaled qu'en 2004, à Paris, pour la sortie de la première version en français de son roman. Je l'ai retrouvé tel qu'en lui-même le succès ne l'avait pas changé : calme, attentif, courtois. Persuadé qu'il ne parlait qu'anglais, langue de nos correspondances, j'ai été stupéfait de le retrouver parfaitement francophone, alors qu'il n'a passé que quatre ans dans notre pays. Mais s'il parle et comprend le français, il ne peut pas l'écrire parfaitement.

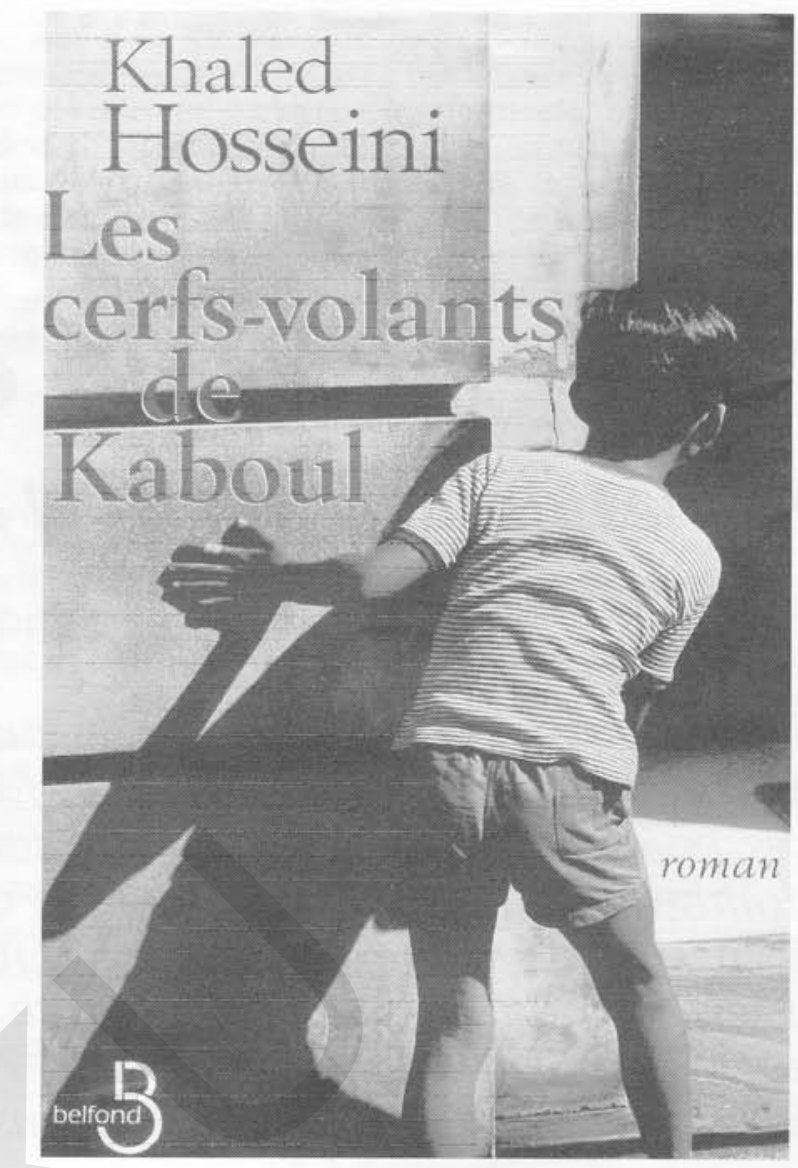

L'histoire de ce roman est d'abord celle de Khaled

En France, son roman a aussi connu un remarquable succès, figurant dans toutes les listes des meilleures ventes de 2005. Edité par le Grand Livre du mois et publié en livre de Poche, Les cerfs-volants de Kaboul a obtenu en 2006 le prix de RFI et celui des lectrices du magazine Elle.

Il y a un an, les productions Dreamworks Films ont acquis les droits de tournage du roman, à un moment où Khaled avait demandé une année de congé sabbatique pour écrire son deuxième roman, ne souhaitant pas renouveler l'expérience épuisante de l'écriture du premier. Ce deuxième ouvrage, dont les personnages principaux sont des Afghanes devrait paraître à la fin de 2006 aux Etats-Unis.

Dans l'attente du film et du deuxième roman issus du talent et de la mémoire de Khaled Hosseini, je lui souhaite une longue vie de créateur, inscrite dans une expression littéraire afghane nouvelle qui n'en est qu'à ses débuts.

1 Deux romans : Terre et cendres et Les mille et une maisons du rêve et de la terreur et un livre de photos et textes de souvenirs et témoignages Le retour imaginaire sont parus aux éditions POL. Les deux romans ont fait l'objet de nombreuses traductions et Atiq Rahimi, documentariste de formation a tourné le film tiré de Terre et cendres, présenté au festival de Cannes 2005, où il a obtenu le prix Regard surl'avenir.

2 Ocre fatal. Editions Balland ('ouvrage n'est plus disponible depuis la disparition des éditions Balland, mais doit être repris par Jacques André Editeur à Lyon). Assem est également l'auteur d'un essai sur Les guerres d'Afghanistan également paru chez Balland et qui pourrait aussi trouver un nouvel éditeur, tandis qu'Assem a publié aux Etats-Unis une biographie du président Daoud, non traduite en français.

3 Les cerfs-volants de Kaboul. Editions Belfond. 


\title{
La botte et la plume
}

\section{La vie littéraire à Kaboul avant et pendant l'occupation}

\author{
par Nadjib MANALAÏ
}

\begin{abstract}
Tout Afghan connaît de nombreuses poésies sur lesquels il s'appuie pour exprimer un état d'âme ou bien faire passer un message. Le plus souvent ces poèmes se transmettent oralement. Mais lire n'est pas naturel. De nombreux obstacles s'y opposent : économiques, techniques, politiques. Les écrivains sont rares, la publication est difficile, l'babitude de lire n'est pas ancrée. Nadjib Manalä̈ évoque ce que fut la vie littéraire et ses paradoxes en Afghanistan dans les années 70 et 80, s'arrêtant volontairement à la fin de la période soviétique, car ensuite c'est une autre bistoire.
\end{abstract}

Vers la fin des années 1960, l'Afghanistan vivait sa première expérience démocratique. La constitution de 1964 reconnaissait le droit des Afghans à s'organiser en partis politiques et à s'exprimer librement. Même si la loi qui devait organiser le fonctionnement des partis politiques ne vit jamais le jour, et la liberté d'expression était strictement encadrée par une censure implacable, il commençait à y avoir un réel espace de création littéraire.

Mise à part une poignée de publications politiques au tirage limité, la quasi-totalité des journaux et revues dépendaient du gouvernement. Tout article proposé était lu et relu à différents niveaux. Il fallait que rien ne soit publié qui ne fût du goût des gouvernants. Les articles en prose avaient essentiellement une visée éducative, didactique ou de propagande. La littérature narrative, quasiment inexistante, était presque exclusivement centrée sur la mise en évidence d'un besoin modéré de modernité. Même la poésie devait rester dans les sphères éthérées des nobles sentiments et des belles paroles pour être publiée. On parle encore aujourd'hui des fameux vers de Mawlâna Khâl Mohamad Khasta qui avaient provoqué, paraît-il, un véritable séisme dans Kaboul :

Par cent preuves et arguments, le vrai ne pourrait se montrer

Tant qu'il reste, aux porteurs de turbans, une artère au cou.

Que le système fût étouffant n'est pas qu'une figure de style. Le régime verrouillait tout : Il y avait bien quelques journaux d'opinion qui donnaient corps à une démocratie naissante, mais leur liberté avait des limites peu élastiques. Rares sont les journaux qui ont pu vivre au-delà de quelques mois. D'ailleurs, même les journaux indépendants étaient imprimés par les presses gouvernementales.
Les textes d'opinion étaient recopiés à la main, ou parfois dactylographiés dans les bureaux et reproduits au papier carbone. C'est aussi sous cette forme que circulaient les textes littéraires qui ne passaient pas la barrière de la censure.

Avec le coup d'Etat de 1973, la courte expérience démocratique de l'Afghanistan fut brutalement interrompue. Même la poignée de journaux politiques furent interdits et l'Etat se retrouva de nouveau en position de monopole pour tout ce qui concernait l'écrit.

\section{Une terre assoiffée}

Décrire l'Afghanistan comme une terre de poésie est devenu, presque, un lieu commun. Mais un siècle après les débuts de l'édition dans le pays, cette terre de poésie était assoiffée de littérature.

Le manque de littérature en langue dari était partiellement comblé par l'importation de livres iraniens. Encore que la censure n'épargnât guère l'importation du livre. Quant à la littérature pachto, les seules sources d'approvisionnement étaient les presses gouvernementales afghanes et quelques ouvrages lithographiés au Pakistan. Les librairies étaient rares, les bouquinistes vivotaient et les livres étaient hors de prix !

Le coup d'Etat de 1978 amena au pouvoir une autre frange de la société afghane. Une frange qui se disait muselée, opprimée, exploitée sous l'ancien régime et qui s'empara brutalement de tous les leviers de l'action sociale, politique et culturelle.

Les révolutions ne sont pas seulement violentes et revanchardes, elles sont aussi extrêmement bavardes. La révolution d'avril ne faisait pas exception. Elle avait d'autant plus besoin de parler qu'elle n'avait aucune assise populaire et que le parti de "l'avant-garde de la classe ouvrière " était resté très éloigné des masses laborieuses. Il lui fallait convaincre le peuple qu'il avait été libéré du joug écrasant du féodalisme. 
L'épuration politique de l'appareil de l'Etat, la répression aveugle des opposants et de ceux qui auraient pu éventuellement en faire partie, s'accompagnait donc d'une espèce de révolution culturelle. Les droits des minorités étaient reconnus, et des journaux en langues paçhaï, ouzbek, turkmène et balotchi commençèrent à paraître.
Autrefois, les journaux gouvernementaux étaient des publications bilingues avec des articles les uns en pachto et les autres en dari, mais, la parole révolutionnaire devant parvenir à tout le monde, on jugea plus opportun de traduire les mêmes discours, la même propagande dans toutes les langues. Ce qui conduisit à un accroissement considérable du nombre et du tirage des publi-

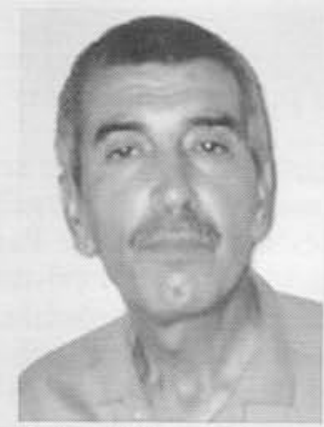

Wâssef Bâkhtari est né en 1942 à Balkh. Après avoir étudié la littérature dari à l'université de Kaboul (1966), il travailla un temps au ministère de l'Education nationale dans l'édition des livres scolaires. En 1974 il eut l'opportunité de poursuivre ses études à l'Université de Columbia (New York) où il obtint une maîtrise en Sciences de l'éducation. II occupa également quelque temps le poste de directeur de publication de la revue Zhwandoune.

Il fut arrêté en 1978 et passa un an et deux mois dans la prison de Pol-e Tcharkhi.

Fin connaisseur de la littérature persane classique (il connaît, dit-on, par cœur des dizaines de milliers de vers) et de la mythologie universelle, Bâkhtari manie la langue dari avec une précision rarement égalée. Membre de la Société des Ecrivains d'Afghanistan, il a joué un rôle formateur de premier plan auprès des jeunes poètes et écrivains. L'emprunte de Bâkhtari est visible chez la plupart des poètes afghans de langue dari qui ont émergé au cours des deux dernière décennies.

S'il ne fallait retenir que deux noms dans la poésie dari du vingtième siècle je dirais sans hésiter Khalili et Bâkhtari.

Le poème ci-dessous a été écrit en 1973, peu après le coup d'Etat de Mohammad Daoud. II dépeint une atmosphère suffocante de loi martiale. N. M.

\section{Les portes closes du temps}

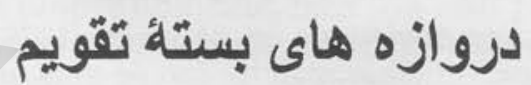

Dites à l'araignée,

Dans ce langage

connu des seuls conteurs du vent :

Tends la toile de ta vie,

Lèpre géométrique de lignes, de surfaces et d'intervalles,

De part en part

Entre les angles des instants assoiffés de l'aube

Et sur la face des murs verts des révélations.

Que le portique de nos demeures soit le lieu de ta victoire!

Si au milieu de la nuit,

Lors de la fuite des assaillants aux paroles de lumière,

Tu vois la patience des enfermés, le silence des voilées

Glisser à l'oreille des fenêtres :

"Puisse, le pouls de la noblesse battre en silence ! " :

Et si tu vois la main de l'aventure

Jeter, des sommets de la tragédie,

La graine des liens,

N'épargne pas ton rire à notre deuil !

$\mathrm{Ne}$ crains pas le souffle rouge des nuées.

Car le grondement du tonnerre nocturne,

N'appartient pas au peuple des bédouins

Mais à la famille stérile des intervalles.

Dites à l'araignée

Que le portique de nos demeures soit le lieu de ta victoire !

$$
\begin{aligned}
& \text { به عنكبوت بكوييد } \\
& \text { به آن زبان كه جز راويان باد ندانند } \\
& \text { نسيج هستى خويش نان } \\
& \text { جذام هندسى خط و سطح و فاصله راني } \\
& \text { بهر كر انه بكستر } \\
& \text { ميان زاوية لحظه هاى تشنه صبح } \\
& \text { و بر صحيفل ديوار هاى سبز بشارت } \\
& \text { رواق خانه ما باركاه فتح توباد }
\end{aligned}
$$

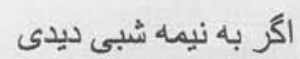

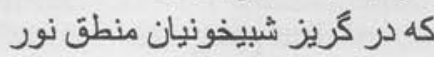

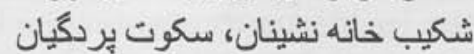

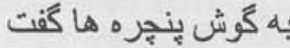

صداى نبض نجابت خموشتر باد كنادا

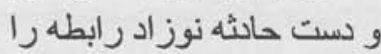

زبام فاجعه افكند

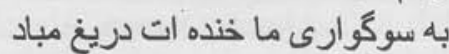

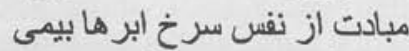

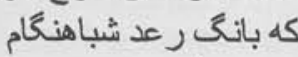

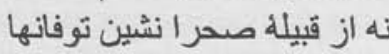

كه از تبار عقيم خطوط فاصله بود نئه

به عنكبوت بكويّيد

رواق خانه ما باركاه فتخ تو باد بلد 
cations, mais en même temps à un appauvrissement du contenu.

Les textes d'avant la révolution que la censure " féodale " avait condamnés au secret (dans de rares cas, ils avaient été diffusés sous forme manuscrite, dupliqués au carbone) se virent offrir tout l'espace des publications gouvernementales. On constata même une amélioration très visible de la qualité matérielle des publications (papier, encre, typographie, orthographe...).

Le nouvel espace littéraire était, certes, au service d'une idéologie, mais il y avait un véritable foisonnement. Ce foisonnement révolutionnaire n'allait pourtant pas durer longtemps. En l'espace de quelques mois plusieurs milliers d'intellectuels et de gens de lettres se retrouvèrent derrières les barreaux des centres de détention, d'autres quittèrent le pays. Le climat de méfiance entre les différentes composantes du parti au pouvoir allait achever de miner la dynamique littéraire des premiers jours de la révolution.

Dans le même temps, des traductions persanes des œuvres soviétiques arrosaient le marché.

Une conséquence importante de l'inflation des publications fut la gratuité ou la quasi gratuité des livres et journaux. (Un quart de siècle après, les médias afghans payent le prix catastrophique de cette gratuité : les Afghans ont perdu le réflexe de l'achat de livres !)

\section{Ceux qui partirent et ceux qui restèrent}

L'invasion soviétique en décembre 1979, s'accompagna d'une véritable marche forcée vers une soviétisation de la société afghane. La création des multiples syndicats et organisations professionnelles en était une marque. C'est ainsi que dès 1980 fut créée la " Société des Ecrivains de l'Afghanistan ".

Pour se faire accepter, le gouvernement de Babrak Karmal issu de l'invasion soviétique entrouvrit les portes des prisons. Très vite un grand nombre d'intellectuels quittèrent le pays. Restaient à l'intérieur ceux qui faisaient partie du régime et ceux qui n'avaient pu trouver le moyen de s'en aller.

La soviétisation ne conduisit pas pourtant à la mort de la littérature afghane. Il y avait, c'est un fait, plusieurs poètes et écrivains de tout premier plan parmi les cadres dirigeants du parti : Solayman Laeq, Bareq Chafii, Amin Afghanpour, Dastagir Pandjchiri, Karim Missâq, Mohamaddine Zhwak pour ne citer que les plus remarquables. De plus, les contradictions insurmontables entre les idéaux d'avant la prise de pouvoir et la réalité du pouvoir étaient difficiles à vivre pour les intellectuels communistes pris dans la tourmente ${ }^{2}$. Aussi, malgré le fait que la propagande s'octroyât la part du lion, quelques écrivains indépendants (Zarine Anzor, Qahâr Assi, Wâssef Bâkhtari, Zalmay Hewadmal, Rahnaward Zaryab, Spojmaï Zaryab, Sediq Rohi, Habibollah Rafi, Akram Osman, Abdolchokour Rechad, Obaydollah Mehak, Leilâ Sarahat Rochani et bien d'autres) parvenaient à faire publier, de temps à autre, des œuvres qui se situaient en dehors des lignes officielles. La plupart des ces écrivains avaient développé, déjà sous les régimes précédents, des stratégies de contournement pour pouvoir délivrer leur message malgré la censure. Ils utilisèrent les mêmes moyens face à la soviétisation de la littérature.

La résistance ne cessant de se renforcer, les stratèges soviétiques et leurs disciples afghans voulurent appliquer en Afghanistan une recette qui avait donné des résultats satisfaisants en Union Soviétique : sous couvert de reconnaître les droits des minorités, ils élevèrent les ethnies au rang de " Nationalités " qu'ils voulurent dresser les unes contre les autres. C'est ainsi que des milices ethniques virent le jour et que des militants acharnés de l'internationalisme prolétarien en vinrent à développer, et à publier dans "l'organe officiel du parti ", des notions aussi brillantes que celle d'une " majorité sans culture " (qui visait les Pachtounes). Cette dérive fascisante fut à l'origine de bien des drames dans les années qui suivirent.

\section{La "Réconciliation nationale"}

Le vent de " là glasnost et la perestroïka " souffla sur l'URSS qui décida de quitter le bourbier afghan. En octobre 1985, les dirigeants soviétiques convoquèrent au Kremlin leurs amis de Kaboul pour leur annoncer la nouvelle.

Babrak Karmal fut bientôt écarté du pouvoir et son remplaçant, le docteur Nadjib, annonça qu'il s'engageait dans une " Démarche d'Entente Nationale ". Le Parti Démocratique du Peuple d'Afghanistan renonça, non seulement au monopole du pouvoir, mais procéda à une profonde remise en cause idéologique, et finit même par changer de nom. Bien sûr, les mouvements de résistance refusèrent l'idée d'un arrangement avec le régime, mais de nombreuses petites organisations politiques et culturelles fleurirent à Kaboul.

La constitution de 1964 reconnaissait déjà aux Afghans le droit de former des associations, mais ce droit n'avait jamais trouvé un espace suffisant pour être exercé. Avec la Démarche de l'Entente Nationale, de nombreux cercles et associations plus ou moins officiels virent le jour. La direction de la Société des Ecrivains Afghans échappa au contrôle du Parti. Le gouvernement du Dr Nadjib, pour mieux rendre visible la réalité du prétendu pluralisme, mit des moyens relativement importants à la disposition des gens de lettres. De nombreux textes plus ou moins critiques à l'égard du régime ${ }^{3}$ furent publiés sans que la censure s'en offusquât ouvertement.

Paradoxalement, la période communiste peut être considérée comme l'époque la plus fertile de la littérature afghane. Durant les trois dernières années du régime communiste on publia probablement plus de livres que durant les trois décennies précédentes !

L'entrée des modjahedin à Kaboul marqua la fin de cette période de l'histoire littéraire afghane. Les bibliothèques furent pillées, les livres servirent de combustible pour chauffer les bureaux de la nouvelle administration, et un nouvel exode vida le pays de tout ce qu'il comptait comme artistes et gens de lettres. L'Afghanistan fut plongé dans un nouvel abîme littéraire qui dura presque dix ans. Il est vrai que durant cette décennie le silence littéraire à l'intérieur du pays était largement compensé par l'activité artistique et littéraire des Afghans de la diaspora.

1 Je me suis payé mon premier livre neuf de littérature, en 1975 , quand un ami français m'a rémunéré pour le coup de main que je lui donnais dans l'apprentissage du pachto. Le prix d'un classique de la littérature persane équivalait à trois jours de salaire d'un journalier.

2 Dans un de ses récits, Solayman Laeq met en scène un résistant capturé par l'armée. Il aime à raconter que lorsqu'il écrivait cette histoire, il ne pouvait se résoudre ni à faire mourir ce personnage, ni à le faire plier devant la volonté du cadre du Parti qui était chargé de l'interroger.

3 En France on connaît les nouvelles de Spojmaï Zaryab publiées dans un recueil intitulé " La plaine de Caïn " (traduction de Didier Leroy, éditions " Souffle " et "Inventaire "). 


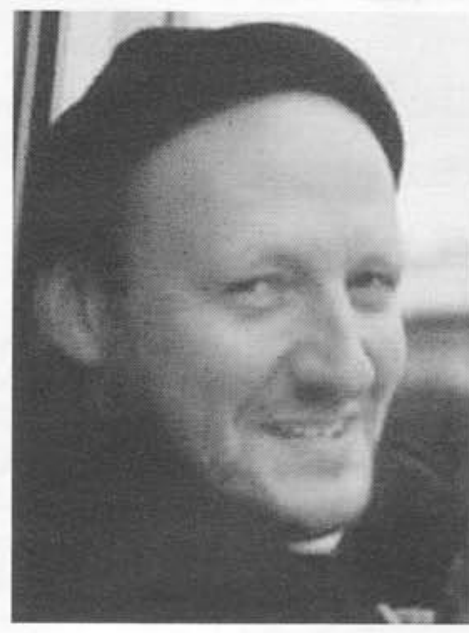

\section{Adieu}

\section{à un poète reporter}

par Jérôme BONY

$\mathrm{L}$

'Afghanistan avait collé à sa vision d'un monde idéal.

Ou plutôt cette parcelle du pays nommée Pandjchir, et les chemins entre neige et ciel qui y memenaient.

Et ces "combattants de l'insolence» qui tenaient tête à l'armée soviétique sous les ordres du commandant Ahmad Chah Massoud. Nous l'avions découvert ensemble à l'été 1981. Des liens particuliers s'étaient naturellement tissés sous les obus, et prolongés au montage quand, devenant personnage principal de notre film "Une vallée contre un Empire », Massoud est entré dans notre univers intérieur.

Christophe de Ponfilly se l'était en quelque sorte approprié. Fidèle en amitié, il retourna le voir maintes fois, ayant du mal à supporter toutefois de devoir courir les montagnes et attendre des jours avant de le retrouver: les choses sont plus simples dans les rêves.

Il avait un besoin quasi vital de se réfugier dans cette vallée emblématique de la résistance, où le bruit de la rivière roulant au milieu des terrasses vertes à flanc de montagne, sous un ciel d'un bleu immuable, lui faisait oublier les tumultes d'un monde dont il supportait de moins en moins les turpitudes.

Puis son héros est mort assassiné, et son pays de têve avec.

Il n'y mit pas les pieds quand beaucoup de journalistes s'y précipitèrent en septembre 2001. Don Quichotte ne se mêlait pas à la piétaille et déjà ce n'était plus son univers.

J'y avais moi-même tout trouvé corrompu par l'argent. En 81, jamais nous n'avions sorti un billet de notre gilet afghan. 20 ans plus tard, une journée en voiture coûtait 100 à 500 dollars, selon les risques.

Quand il y est enfin retourné l'année dernière, c'était pour y faire un film de fiction : "l'Etoile du Soldat». Massoud n'étant plus, il fallait inventer des personnages, dans ce Pandjchir, où les choses ne se sont pas toujours bien passées. Par exemple quand les religieux ont appris que des jeunes hommes couverts d'un tchadri jouaient des rôles de femmes. L'intolérance n'est pas réservée aux Tâlebân. Le Pandjchir aussi a changé et Christophe l'a mal supporté.

Laurence Laumonier, la fameuse "docteur Laurence ", bien connue des Afghans parce qu'elle en a soigné tant, savait que la vision de Christophe était très différente de la sienne. Elle qui avait passé tant de temps avec eux, mais différemment: au sein des familles, avec les femmes, qui lui parlaient beaucoup, elle savaient qu'ils étaient aussi capables de mesquineries. Christophe, lui, ne voyait que des héros, dans des situations exceptionnelles, valorisantes, comme peut l'être la guerre. Mais au retour de son dernier voyage, fin 2005 , il en était à se demander s'il ne s'était pas trompé, et cela l'affectait profondément.

De même que de ne pas voir son film retenu pour la quinzaine des réalisateurs à Cannes. C'est un insatiable besoin de reconnaissance qui l'a poussé à faire, encore et encore, jusqu'à 40 documentaires avant ce film. Non pour sa propre notoriété, bien sûr, mais pour cette quête, qui lui était essentielle, de ce qui reste d'humanité dans ce monde. Sa vie se confondait avec son oeuvre, et cette reconnaissance, il n'a pas fini d'en rece-

\section{Fraternité et exigence}

Christophe de Ponfilly a rejoint Nicolas, Massoud et tous ceux qui, jusqu'au delà de leur sommet, ont gravi ces montagnes de l'Afghanistan.

J'ai connu Christophe il y a plus d'une vingtaine d'années, au Pakistan, au retour d'un de ses périples afghans. Celui-là même qui servira de trame à "L'étoile du soldat". Je me rappelle aussi bien sa douche réparatrice que ses regrets d'avoir dû, face à la raison des Etats, laisser Nicolaï au fil de son tragique destin.

J'ai retrouvé Christophe, en septembre dernier, sur le tournage de "L'étoile du soldat" dans la vallée du Pandjchir. On a déjeuné ensemble dans la "base soviétique" reconstituée, entre deux prises de vues.

Christophe était, comme à son habitude, entier dans son projet. Dans l'objectif de la caméra, l'Afghanistan des " moudj " rencontrait (avec quelques "réglages"....) celle du processus de Bonn. En contrebas, les campements koutchi portaient avec eux cette temporalité, aussi immuable qu'en mouvement, si chère à Christophe.

Cette histoire d'hommes et d'images était la sienne. fidèle et généreuse. Le message de fraternité et d'exigence que laissent le témoin et le cinéaste continuera à inspirer notre action au service d'un Afghanistan en paix et d'un monde plus solidaire.

J'étais la semaine dernière dans le Pandjchir. Les koutchis sont de retour. Le "décor" de Christophe nous serre le coeur.

Régis Koetschet 


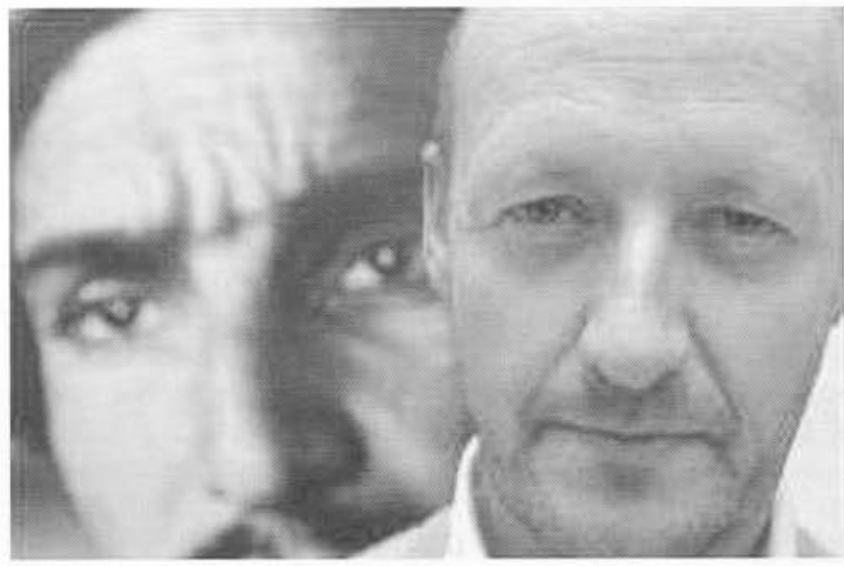

voir, de la part de tous ceux qu'il a touchés par sa sincérité, et sans doute encore à la sortie de $\mathrm{l}^{5}$ "Etoile» en novembre.

Il avait fait une version en dari de "Massoud l'Afghan" et l'avait projetée dans la vallée: un jour, en 2001, quand j'y étais retourné pour le news, un Panddjchiri m'avait interpellé, remercié de mon film : je lui ai dit qu'il se trompait, mais pas de beaucoup : je connaissais bien Christophe. Nous avions ri, comme les Afghans aiment tant le faire. Comme Christophe, qui savait saisir la vie, avait su le montrer. Eclats de rires, parmi les éclats d'obus.

Et bien sûr que son Afghanistan que notre Afghanistan est encore un peu là.

\section{Un grand ami de l'Afghanistan}

Nous avons perdu un grand Cinéaste et écrivain, un homme de grand talent, mais aussi un être des grandes causes, un bon père de famille, mais aussi un grand ami de l'Afghanistan et des Afghans dans les moments de malheurs comme dans des circonstances heureuses; Au fil du temps il est devenu très proche et ami du Commandant Massoud qu'il a compris dès 1980 lorsqu'il lui a installé une petite station de radio, qu'il a soutenu ardemment et fait connaître plus que quiconque en France et ailleurs, dans ses innombrables oeuvres dont Massoud l'Afghan, devenue célèbre.

II venait souvent me voir, comme son frère Jean, à l'Ambassade, ou encore il me livrait des petites anecdotes ou confidences dans notre restaurant favori de la Place de la Muette. Ce qui me frappait toujours c'était son intelligence et son humanité, son détachement pour les choses matérielles, son goût du risque, son attachement et sa fidélité indéniables à mon pays. II y a un peu plus d'un an et demi, il est venu me voir en me soumettant le scénario de son dernier film sur l'histoire d'un soldat russe en Afghanistan en guerre contre les Soviétiques - terminé maintenant et qui sera projeté en automne sans lui - que j'ai très vite approuvé et soutenu avec le Chef d'état-major afghan qui l'a beaucoup aidé lors du tournage du film sur le territoire afghan.

II a beaucoup investi, s'est donné énormément pour ce film, son oeuvre grandiose, mais sans savoir que c'était son dernier combat gagné, certes, mais à titre posthume.

Bravo Christophe, adieu Christophe.

Professeur Zalmaï HAQUANI

Ambassadeur d'Afghanistan en France

\section{Christophe de Ponfilly, grand reporter, écrivain, réalisateur et producteur}

Né le 5 janvier 1951 d'un père polytechnicien, Christophe de Ponfilly, qui était père de quatre enfants, s'est suicidé le 16 mai 2006. Après des études de maths et un travail de nègre chez un éditeur, il s'est tourné vers la caméra, le reportage et le documentaire dans les années 1980. Il laisse une oeuvre engagée, marquée par la personne de Ahmad Chah Massoud, assassiné le 9 septembre 2001. Il l'avait rencontré en juillet 1981 lors de son premier voyage en Afghanistan et l'avait ensuite retrouvé lors de ses nombreux voyages en Afghanistan. C'est en 1981 qu'il réalisa son premier film sur l'Afghanistan, en super 8, avec Jérôme Bony "Une vallée contre un empire".

Grand admirateur de celui qu'il a qualifié de "Lion du Pandjchir", il voyait en lui un homme de foi, respectueux et pacifique. Mais il s'est aussi intéressé à d'autres sujets comme le poète russe exilé "Joseph Brodsky" (1989), l'écri vain français "Antoine Blondin" (1995), "Naître, des histoìires banales, mais belles" (1994), "Nos enfants de la paatrie" (1993), ou encore "Femmes d'Asie centrale" (2004).

Fondateur avec Frédéric Laffont de l'agence Interscoop (créée en 1983), de la société de longs métrages Albert Films (1999) et de la société de distribution Doc \& Co (1996), il a écrit, outre des adaptations de ses films, cinq livres:

- "Le clandestin - Dans la guerre des résistants afghans" (document), éditions Laffont, 1984.

- "Les gobeurs de lunes 》 (roman) éditions Laffont 1987, réédité sous le titre "Scoops » aux Ed. du Félin, 2003.

- "Poussières de guerre » (document), Ed. Laffont, 1990.

- " Massoud, l'Afghan » (document), Arte éditions et Ed. du Félin, 1998.

- "Vies clandestines " (document), Ed. Florent Massot Prix littéraire des droits de l'homme 2001.

- "Lettre ouverte à Joseph Kessel sur l'Afghanistan " (document), Ed. Bibilophane, 2002.

Il est l'auteur d'une quarantaine de reportages et de documentaires, dont un grand nombre furent consacrés à l'Afghanistan -et lui valurent des prix comme "Massoud l'Afghan" (1998), "Les combattants de l'insolence" (prix Albert Londres en 1985) et "Poussières de guerre". Il réalisa aussi pour FR3 les séries "Zanzi Bar" (1993-1995) et "Aux p'tits bonheurs, la France" (1998). Il venait de terminer, avec le soutien d'Eurimages, son premier film de fiction "l'Etoile du soldat", dont la sortie est prévue en salle fin 2006 et dont le livre a été publié chez Albin Michel. Ce film relate les aventures d'un jeune appelé soviétique envoyé en Afghanistan, qui est fait prisonnier par Massoud et découvre le véritable visage de ceux qu'il était censé combattre.

Celui qui, dans "Massoud l'Afghan", se demandait si « dans le tumulte d'images et de sons du monde moderne, tenir une caméra a encore un sens » n'a cessé tout au long de sa vie de défendre un journalisme de témoignage face à l'exploitation télévisée des horreurs du monde et à l'information spectacle.

Ph. FRISON 


\section{GHRONOLOCIE}

\section{Mars}

- Le 1: Le Président Karzaï rejette la demande des Conseils provinciaux de nommer eux-mêmes les gouverneurs ou les chefs de police.

Sur la route de l'Inde, puis du Pakistan, le président Bush s'arrête à Kaboul pour une visite surprise de quelques heures.

- Le 2 : Miran Shah (Pakistan) est occupé par des membres des tribus locales lourlourdement armés. Les forces pakistanaises en reprennent le contrôle le 6.146 personnes auraient été tuées durant les combats.

Dans ie nord, escarmouche entre des hommes du au général Malik et des proches de Rachid Dostom.

Les travaux de construction des $122 \mathrm{~km}$ de la route Kunar-Djalalabâd reprennent après un long arrêt.

- Le 4 : Le président Karıdï lance une campagne nationale anti-p:li.o. 7,2 millions d'enfants de moins de $\Sigma$ ans seront vaccinés à travers le pays avec l'aide de 40.000 volontaires. L'Afghanistan fait partie des quatre pays encore affectés par le virus de la polio dans le monde.

Un officier canadien est grièvement blessé par un militant tâleb à l'aide d'une hache.

$942 \mathrm{~kg}$ de drogue sont saisis et brûlés à Hérat. Des fonctionnaires de police impliqués dans ce trafic sont arrêtés.

Un officier des forces spéciales françaises est tué au cours d'un engagement avec des Tâlebân, au nord de Kandahar.

- Le 5 : Des attaquants brûlent deux camions du Programme Alimentaire Mondial, détruisant 29 tonnes d'aide alimentaire destinées à la province d'Orouzgan.

- Le 7: Le Secrétaire général des $\mathrm{Na}$ tions unies relève que "durant le deuxième semestre de 2005 et le début de 2006, la fréquence des attaques (200 par mois) a dépassé les niveaux atteints pendant les périodes [précédentes]》. "Le phénomène le plus préoccupant est peut-être la forte augmentation des attentats-suicidess.

- Le 8: Le gouvernement commence une nouvelle campagne d'éradication de l'opium, visant à détruire 20.000 ha plantés.

Dans le cadre de la journée internationale de la femme, le président Karzaï appelle les dirigeants religieux à soutenir les droits des femmes. Il signe par ailleurs un décret libérant un quart des 110 femmes détenues en Afghanistan.

- Le 9 : Un haut responsable américain prévoit une escalade de la violence au printemps et cet été, découlant du déploiement des forces de l'OTAN dans des zones où la présence des insurgés est forte.

- Le 12: Arrivée à Kaboul du premier ministre canadien.

Deux civils afghans et deux kamikazes sont tués à Kaboul dans un attentat-suicide visant Sebghatullah Modjaddedi, président du Sénat, qui n'est pas atteint. S. Modjaddedi accuse les services secrets pakistanais.

Quatre soldats américains sont tués dans un attentat lors d'une patrouille dans le district de Pech (Kunar).

- Le 14: La plus grande cache d'armes jamais trouvée en Afghanistan est découverte à Cheberghan (Nord).

- Le 15 : Les députés afghans rejettent l'idée du Pakistan de cloturer les frontières avec l'Afghanistan ce qui équivaudrait à reconnaître la Ligne Durand.

La Banque mondiale approuve une subvention de 40 millions de dollars pour le Programme National de Solidarité qui aidera les communautés rurales. $88 \%$ de cette aide concerne des programmes d'infrastructure concernant l'irrigation, les routes, la fourniture d'eau potable et l'électricité.

Naghma, chanteuse populaire afghane née à Kandahâr, arrive à Kaboul pour le Naoruz, après 14 ans d'exil.

- Le 17 : Le gouvernement commence la distribution de terrains pour les réfugiés dans le district d'Aqchi (province de Djaozdjan). 8000 lots seront alloués au prix de 2000 afghanis le lot. A terme 300 000 terrains doivent être distribués.

Neuf policiers sont tués en ramenant les corps de quatre Albanais enlevés dans la province de Kandahar.

- Le 18: Tadj Mohammed, dit Qari Baba, et quatre de ses hommes sont abattus dans la province de Ghazni. Qari Baba fut un commandant important du Harakat-e Enqelab.

Les forces spéciales néerlandaises en Afghanistan auraient, à deux reprises, remis des terroristes présumés à l'armée américaine. Cette affaire embarrasse le gouvernement néerlandais qui a critiqué plusieurs fois les violations du droit humanitaire commis par les Etats-Unis .

Chrétien afghan
- Le 19: La police afghane arrête un mu-
sulman du nom d'Abdul Rahman converti au
christianisme. II doit être inculpé d'apostasie
et encourt la peine de mort s'il refuse de
renoncer à cette conversion. Le secrétaire
dEtat allemand à la Défense soulignele 21 que
son pays "participe à la stabilisation du pays
avec 2450 soldats afin que l'Afghanistan
devienne démocratique, et non pas pour que
des peines de mort soient prononcées pour
des motifs religieux". Amnesty Internatio-
nal relève pour sa part que la Constitution'
afghane engage le pays à se conformer aux
tex- tes internationaux qui reconnaissent la
liberté de culte. Benoit XVI exprime son
inquiétude dans un message au président
Karzai.. Des dignitaires religieux afghans
mettent en garde pour leur part contre toute
intervention du président Karzaï, brandissant
la menace d'une révolte. La présidence
afghane indique que l'affaire doit 'être
traitée par le seul pouvoir judiciaire, qui est
indépendant. Le 22 la Cour suprême afgha-
ne indique qu'Abdul Rahman pourrait échap-
per à la mort en raison d'un problème mental.
Le 27,700 personnes manifestent à Mazar-
e Charif contre la libération du converti. Le
même jour, il est libéré de prison. II est en-
suite accueilli en ltalie.

- Le 19 : Plus de 40 laboratoires de production d'héroīne ont été détruits dans la province du Nangarhâr.

- Le 22: Hâmed Karzaï dévoile la compo- sition du gouvernement qu'il va soumettre au Parlement. Le ministre des Affaires étrangères, Abdoullah Abdoullah ne fait plus partie du nouveau cabinet. Il aurait refusé plusieurs postes moins importants. Sur les 25 ministres proposés (contre 27 précédemment), trois ministres changent de portefeuille et huit nouveaux font leur entrée.

- Le 23 : Le Conseil de sécurité proroge à lunanimité le mandat de la Mission d'assistance des Nations unies en Afghanistan pour une nouvelle période de 12 mois.

Le Pakistan proteste auprès de l'Afghanistan après la mort de 16 hommes tués la veille par les forces afghanes près de Spin Boldak. Le 31 : Les autorités afghanes arrêtent le chef de la police frontalière responsable de cet incident. Il au- 
Bouddhas: Le cinéaste suisse, Christian Frei, vient de réaliser «Les Bouddhas Géants ", documentaire de $90 \mathrm{mn}$ dans lequel il affirme que les Bouddhas de Bamiyan ont été détruits sur ordre d'Ossama Ben Laden pour des raisons symboliques, alors que Mollah Omar y était opposé. La démolition aurait été l'oeuvre d'ingénieurs pakistanais et saoudiens. (RFE/RL 20/03 et The Daily Times 29/03)

Pillages: Près de quatre tonnes d'objets d'art ancien d'Afghanistan ont été saisies depuis deux ans en Grande-Bretagne, provenant de pillages de sites archéologiques. Sur ces quatre tonnes, trois concernent des céramiques, des sculptures, des statues d'art du Gandhara, des armes en bronze et des monnaies datant du $3^{\mathrm{e}}$ siècle av. J.C. La plupart de ces objets ont gagné les réserves du British Museum. Les responsables afghans et britanniques pensent en effet que pour le moment l'Afghanistan n'a pas les moyens d'en assurer la sécurité. (The Sunday Times 12/03)

Drogue : Selon le rapport 2005 de l'agence onusienne des drogues et du crime la culture du pavot rapporte 560 millions de dollars aux paysans afghans. Les trafiquants empochent, quant à eux, 2,14 milliards de dollars. L'opium fait vivre deux millions d'Afghans. Le gouverneur de la province de l'Helmand a appelé les barons de la drogue à investir l'argent du trafic dans l'économie afghane au lieu de le placer à l'étranger, principalement dans des banques des Émirats Arabes Unis. Le gouvernement pourrait leur garantir l'immunité s'ils acceptent d'arrêter le trafic, de faire allégeance au pouvoir central, d'investir en Afghanistan et de payer des impôts sur les sommes gagnées illégalement. (Bassirat avec AFP et AP 05/04)

Ariana : La liste, publiée le 22 mars, des 92 compagnies aériennes auxquelles l'Union européenne interdit ses aéroports pour des raisons de sécurité mentionne certains avions d'Ariana Afghan Airlines. De ce fait Ariana doit sous-traiter ses vols vers Francfort, sa seule destination en Europe, à un groupe français, Eagle Aviation. Un plan de restructuration d'Ariana prévoit que 500 à 700 personnes y seront employées au lieu de 2000 actuellement. En novembre Ariana commandera quatre nouveaux Boeing 737-700 qui seront livrés en 2009. Les deux Boeing 757-200, livrés en 2005, seront gérés cette année par un groupe britannique pour de nouvelles lignes vers l'Europe (Hambourg et Amsterdam). (AP 22/03, AFP 17/04)

Ecoles : constructions : Le ministère de l'Éducation veut construire 2000 écoles en 2006. II prévoit également des mesures afin de permettre aux enfants d'ètudier dans les zones où sévit la guérilla. Selon les données de I'UNICEF, près de 5 millions d'enfants ont été scolarisés en 2005, soit un million de plus que l'année précédente. Le taux de scolarisation des filles est en progression. Plus de 7000 écoles n'ont pas encore de structures en dur. $80 \%$ des écoles ont été construites ou reconstruites par.des ONG. (NNI 18/05)

Ecoles : destructions : Selon le ministère afghan de l'Education, des groupes armés ont brûlé 43 écoles l'an dernier. La plupart de ces écoles se situent dans les provinces de Kandahâr, Helmand, Logar, Zâbol, Laghman et Kunar. (ShortNews 28/03)

Corps enseignant: Selon le ministère de l'Education, il y aurait 150000 enseignants en Afghanistan. Environ 300 professeurs sont titulaires d'un master, 6000 ont une licence, 8000 ont une formation de maitres, 70000 ont le niveau de fin du secondaire. Le reste a un niveau scolaire de base. (Pajhwok Afghan News 27/04)

Stinger : Des pilotes américains et britanniques auraient été la cible de missiles solair. Les Tâlebân auraient reçu des pièces détachées pour missiles Stinger susceptibles d'être utilisés contre les hélicoptères américains en Afghanistan. (The Independant 15/03)

Drones : Une flotte de drones de fabrication française sera sous peu opérationnelle à des fins de reconnaissance au-dessus de la région de Kandahâr. Ils doivent repérer des insurgés avant qu'ils ne deviennent une menace pour les soldats canadiens déployés au sol. (Presse Canadienne 18/03)

Tourisme : L'Afghanistan a participé pour la première fois à la plus grande foire du tourisme dans le monde dans la capitale allemande. (Xinhua 08/03)

Bourses : Suite à l'offre indienne de 500 bourses près de 12000 étudiants se sont portés candidats (6500 à Kaboul, 2500 à Djalalabâd, 1500 à Mazar-e Charif, 650 à Hérat et 420 à Kandahâr). (IANS 08/03)

Tuberculose : Selon l'OMS, 70000 nouveaux cas de tuberculose sont recensés chaque année en Afghanistan et 20000 personnes en meurent tous les ans. Les deux tiers des malades sont des femmes. La tuberculose sévit principalement dans les provinces de Kandahâr, Helmand, Zâbol, Ourouzgân et Day Koundi. (Bassirat avec IRIN 30/03) Influence iranienne : Petit à petit, l'Ouest afghan entre dans l'orbite économique de l'Iran. La plupart des produits en vente dans la région proviennent d'Iran. L'influence iranienne se fait également sentir par le biais des télévisions iraniennes qui diffusent régulièrement des reportages stigmatisant l'occupation de l'Afghanistan par les forces américaines. (Bassirat 23/03)

Groupes armés : 1800 à 2000 milices privées seraient encore à l'oeuvre en Afghanistan. Un total d'un million d'armes seraient entre les mains de milices dans le Nord de l'Afghanistan. (Bassirat et agences 10/04)

(Source: Bulletin du CEREDAF) rait agi pour des raisons personnelles.

- Le 25: Des combats opposent des Tâlebân aux forces américano-afghanes dans la province de l'Helmand, faisant huit morts, sept Tâlebân et un soldat américain. Le 28 , six militaires afghans et quatre personnes dont un Namibien sont tuées dans la même province.

- Le 29: Les autorités afghanes renvoient 38 prostituées étrangères arrêtées dans des bars de la capitale.

- Le 30: La Chine remet un bâtiment équipé abritant les bureaux de l'hôpital Djamhuriat au gouvernement afghan. Les coûts de construction sont estimés à 20 millions de dollars.

Au moins 60 civils trouvent la mort lors de trois jours de combat dans le district de Gerechk (Helmand). Les forces de la coalition déclinent en être la cause contrairement à ce que prétendent certains témoins.

\section{Avril}

- Le 1 : Le président du conseil de province de Takhar (Nord-Est) est assassiné.

- Le 3: L'Afghan Special Narcotics Force, unité d'élite de la police afghane, mène une opération visant le marché de la drogue de Bahram Chah, au sud de la province de l'Hẹlmand. Ce marché a la réputation d'être l'un des plus importants du pays. Plus de 1000 trafiquants y seraient actifs. Une autre opération est menée dans la région de Zarandj (Nimrouz).

L'Afghanistan ferme son consulat de Peshawar suite aux attaques de manifestants contre celui de Quetta.

La police appréhende 16 personnes effectuant des fouilles clandestines dans la province de Ghazni.

Un ingénieur turc travaillant sur un projet de route à la frontière des provinces du Nimruz et de Farah est abattu par des Tâlebân présumés.

- Le 4: Des chirurgiens français réalisent la première opération à coeur ouvert en Afghanistan, sur une fillette de 13 ans.

- Le 7 : Un "conseil des anciens" représentant des habitants du Nord-Waziristan exige le retrait de l'armée pakistanaise suite à des combats violents dans la région. Le Pakistan a déployé 80.000 soldats dans le Nord-Waziristan et les zones tribales voisines.

- Le 8: L'Institut Médical Français pour l'Enfant, construit à Kaboul par Enfants Afghans et qui offre une qualité de soins inconnue en Afghanistan, est inauguré par Bernadette Chirac et le président Karzaï. L'équipement, pour quelque 8 millions d'euros, a été financé pour l'essentiel par des mécènes français. L'Aga Khan prend en charge l'essentiel du budget de fonctionnement (environ 3 millions de dollars en 2006). Quelque 150 Afghans, dont 
13 médecins, appuient les équipes médicales françaises tournantes et les quatre permanents médicaux de l'ONG

Pour forcer les réfugiés à rentrer chez eux le Pakistan ordonne la fermeture des écoles dans les camps de la Province de la Frontière du Nord-ouest.

Un centre de santé pour femmes est inauguré à Mehterlam, (Laghman). L'ONG française AMI pourvoit le centre en médicaments.

- Le 9: Des inconnus tuent cinq personnels de santé et mettent le feu à une clinique dans la province de Badghis.

Le président Karzaï arrive à New Delhi pour une visite d'Etat de cinq jours. Il est accompagné par dix ministres. Le 10 , l'Inde s'engage pour 50 millions de dollars supplémentaires en faveur de la reconstruction de l'Afghanistan.

Un porte-parole des Tâlebân estime que la détermination du peuple canadien est faible, et qu'à mesure que les attentats se multiplieront, les Canadiens vont rappeler leurs soldats. Les insurgés auraient recruté 180 kamikazes pour commettre des attentats contre les Canadiens à Kandahâr au cours des prochaines semaines. Des commandants de la coalition disent au contraire que les Tâlebân sont marginalisés et ont du mal à trouver de l'argent et des recrues.

- Le 10: Le ministère de la diaspora afghane et l'Organisation Internationale des Migrations lancent un programme de retour pour 210 Afghans qualifiés des pays voisins.

- Le 11: Six enfants sont tués et une dizaine blessés lors d'une attaque sur une école près d'Asadabad (Kunar).

- Le 12: Les forces américaines lancent une vaste offensive dans la province de Kunar pour reprendre le terrain stratégique et psychologique occupé par les Tâlebân ces dernières semaines à coups d'attentats et d'opérations commando. Quelque 2500 miltaires américains et afghans participent à l'offensive qui débute par des bombardements aériens dans la vallée de la Pech.

Les forces pakistanaises annoncent avoir tué dans le Nord-Waziristan un membre égyptien d'Al-Qaïda, suspecté d'avoir eu un rôle dans le bombardement des ambassades américaines en Tanzanie et au Kenya en 1998.

Une opération des forces antidrogue dans le district de Dichou (Helmand) permet la destruction de quatre tonnes d'opium, $80 \mathrm{~kg}$ de morphine, $47 \mathrm{~kg}$ d'héroïne et 2,4 tonnes de produits chimiques. Huit laboratoires neufs sont détruits et un trafiquant présumé abattu. Sept personnes, dont quatre Pakistanais, sont arrêtées.

Une roquette atteint le bâtiment du ministère afghan de la Défense sans causer de dégâts.

- Le 14: Des enquêteurs américains rachètent sur le marché de Bagram des clefs
USB volées contenant des renseignements militaires sensibles, entre autres une liste d'espions afghans pour l'armée américaine, des listes de noms de responsables afghans accusés de corruption ou encore des précisions sur le système de défense américain.

Des soldats canadiens prennent part à des combats à l'ouest de Kandahâr, près de Singesar, ancien fief du mollah Omar. Quarante et un Tâlebân et six policiers afghans sont tués.

- Le 17: Les forces américaines ouvrent une enquête sur le décès de sept civils, tués lors de l'offerisive dans le Kunar.

- Le 18: Le Pakistan annonce que le transit de marchandises indiennes vers l'Afghanistan via Karachi est possible.

- Le 19: Le président kirghiz fixe au ler juin la date butoir pour que soient conclues les négociations avec Washington sur le maintien d'une base aérienne à $\mathrm{Ma}$ nas. Les difficultés concernent le montant du loyer.

Un hôpital psychiatrique financé par le Japon est inauguré dans la province de Hérat.

Une roquette explose dans l'enceinte de la radio-télévision nationale à Kaboul.

- Le 20 : L'Assemblée nationale vote la confiance à 20 des 25 ministres du nouveau gouvernement (voir en pages intérieures). Un Syrien membre important d'Al-Qaïda est tué dans une fusillade avec des agents pakistanais

- Le 21 : Les réfugiés afghans de Kacha Garhi (où vivent 54000 personnes) menacent de brûler leurs véhicules et leurs commerces si le gouvernement pakistanais ne leur accorde pas une année supplémentaire.

- Le 22 : Quatre soldats canadiens perdent la vie lors de l'explosion d'une bombe à $70 \mathrm{~km}$ de Kandahâr.

- Le 24 : La présence du virus H5N1 est confirmée dans les provinces de Kaboul, du Logar, du Nangarhâr et de Kapissa. Les provinces de Laghman et Parwan sont classées provisoirement comme hautement suspectes.

Une opération de la police antinarcotique a lieu à Tcharburdjak (Nimruz). 244 petits laboratoires d'héroïne, 17 tonnes d'opium, 4 tonnes d'héroïne, 2 tonnes de morphine, 970 tonnes de produits chimiques et plus de 50 tonnes de haschich auraient été découverts et 164 personnes arrêtées.

- Le 26: L'Organisation de la Conférence Islamique s'engage pour la construction de 20 centres de santé dans les provinces de Baghlan, Faryab, Paktia, Djozdjan, Parwan, Sar-e Pul, Kapissa, Takhar et Kunduz et inaugure un hôpital à Kaboul dans le quartier de Tchehelsoutoun.

- Le 27: L'agence américaine USAID accorde 40 millions de dollars au minis- tère de l'Education.

Le nouveau ministre des Affaires étrangères déclare que l'amélioration des relations avec le Pakistan est la priorité du pays.

Le représentant spécial de I'ONU en Afghanistan estime qu'à moyen terme il y a de bonnes raisons d'être optimiste sur la situation sécuritaire dans le sud du pays en raison de l'augmentation du nombre et de la qualité des forces armées.

Le Turkménistan efface la moitié de la dette afghane (4 millions de dollars).

- Le 30: Les Tâlebân décapitent un ingénieur indien, enlevé le 28 dans la province de Zâbol. Il était sous contrat avec l'entreprise de téléphonie Roshan, pour étendre son réseau dans le sud du pays.

L'armée britannique va dépenser $63 \mathrm{mil}$ lions de dollars pour acheter 80 véhicules blindés contre les kamikazes en Afghanis$\tan$, mais ils ne seront pas disponibles avant l'été 2007.

Le journaliste américain condamné à deux ans de prison en Afghanistan en juillet 2004 pour des accusations de torture dans une prison clandestine est libéré avec deux mois d'avance.

\section{Mai}

- Le 1: Environ 600 travailleurs des compagnies publiques et privées commémorent la Fête du travail à Kaboul

- Le 2 : Les Pays-bas demandent au Pakistan d'intensifier la coopération en matière d'échanges de renseignements avec leurs forces déployées en Orouzgan dans le but de lutter contre les attaques suicide. Le Pakistan, l'Afghanistan et les EtatsUnis commencent un exercice militaire conjoint de dix jours dans la province frontière du Nord-ouest du Pakistan. 1000 soldats, dont seulement 20 soldats et officiers afghans, y prennent part.

- Le 3: Gul Agha Cherzaï, gouverneur de la province du Nangarhâr, échappe à un attentat à Djalalabâd.

Le président Karzaï fait prêter serment aux vingt ministres agréés par le Parlement.

- Le 4: Le Président adopte la troisième loi sur les Medias en quatre ans. Elle doit encore être votée par l'Assemblée.

Air Arabia, compagnie nationale des Emirats Arabes Unis commence ses vols " low cost » vers l'Afghanistan.

La police arrête dans la province de Kunduz deux contrebandiers détenant 12500 bouteilles d'alcool.

Gulbuddin Hekmatyar déclare vouloir combattre sous le commandement d'Oussama Ben Laden.

Deux proches de Cher Mohammad Akhoundzada, ancien gouverneur de l'Hel- 


\section{Economie}

Banque : La Afghanistan International Bank a lancé le 3 avril les premières facilités bancaires sur internet. (Pajhwok Afghan News 03/04)

PIB : Le gouverneur de la Banque centrale a annoncé le 2 avril que le Produit intérieur brut a augmenté de $14 \%$ en 1384 (mars 2005 - mars 2006), contre $8 \%$ l'année précédente. Ainsi, le PIB par habitant atteint désormais 293 dollars contre 226 en 1383. Au cours de la campagne présidentielle 2004, Hâmed Karzaĩ avait promis d'amener le PIB par habitant à 500 dollars à la fin de son mandat. L'Afghanistan se situe parmi les pays les plus pauvres de la région en terme de PIB/hab. Ses voisins: Tadjikistan (280 dollars/hab. en 2004), le Turkménistan (1340 dollars par hab.), le Pakistan ( 600 dollars/hab.) et l'Ouzbékistan ( 460 dollars/hab.).

Inflation : Selon la Da Afghanistan Bank, durant les 12 derniers mois, le taux d'inflation de l'Afghanistan a atteint $10 \%$ mais les prix des aliments ont baissé de façon significative. Seuls les prix des logements et des produits pétroliers ont augmenté. (Xinhua 02/04)

Pétrole : Les deux bassins géologiques du nord de l'Afghanistan contiendraient 18 fois plus de réserves de pétrole et de gaz que l'avaient estimé les spécialistes de l'Union Soviétique en leur temps. Les réserves du bassin afghano-tadjik seraient à présent estimées à 1,6 milliards de barils de pétrole et celles du bassin de l'Amou-Daria à 12 trillions de $m 3$ de gaz. (AP 15/03)

Mines: Les mines et engins non explosés déposés en plus de vingt ans de guerre tuent ou blessent entre 70 et 100 Afghans tous les mois selon le Programme d'action contre les mines d'Afghanistan. Depuis l'éviction des Tâleban, fin 2001 ce chiffre a été réduit de moitié. Malgré un effort soutenu, mené notamment par 10.000 démineurs, l'Afghanistan reste l'un des pays les plus minés du monde. $90 \%$ des victimes sont des hommes et $50 \%$ des enfants. Des statistiques non officielles font état de 1,5 millions d'Afghans morts ou handicapés suite à ces mines. L'ONU espère que l'Afghanistan pourra être entièrement nettoyé de ces mines vers 2013. (AFP 03/04. Xinhua 24/04).

Téléphone mobile : Plus de 1,1 millions d'Afghans, soit près de $5 \%$ de la population, sont clients d'une des deux compagnies de téléphonie mobile, Roshan et AWCC, dont les réseaux couvrent plus de la moitié du pays. Le prix est cependant élevé : au moins 50 dollars pour un portable neuf, 25 dollars pour une carte SIM, et au moins 5 dollars pour une carte prépayée. Lancée en juillet 2003, Roshan est actuellement la plus grande société imposée d'Afghanistan (25 millions de dollars en 2005), soit 5\% du budget national. Elle fournirait du travail à 15000 Afghans. (AFP 04/04 \& 09/04) Sang: La France accordera une subvention de 800.000 dollars dans les quatre prochaines années pour l'établissement de cinq banques du sang et des laboratoires d'analyses médicales à Mazâr-e Charif, Hérat, Djalalabâd, Kandahâr et Kaboul. (Pajhwok Afghan News 10/05)

\begin{abstract}
Analyse
Selon Chris Patten, ex-commissaire de I'Union Européenne aux Affaires étrangères, l'une des principales causes de linstabilité en Afghanistan est le Pakistan et son régime militaire appuyé sur des religieux musulmans radicaux. L'armée y occupe une place démesurée. Des élections démocratiques marginaliseraient certainement les partis islamistes qui n'ont obtenu que $11 \%$ des voix lors des élections de 2002. Par ailleurs, un gouvemement civil et démocratique aurait davantage intérêt à instaurer des relations pacifiques durables avec l'Inde.

"La démilitarisation et la « déradicalisation » du Pakistan est véritablement la clé de la stabilité en Afghanistan et de la région qui l'entoure. Les gouvernements qui s'efforcent résolument de soutenir l'Afghanistan le feront en vain tant qu'ils ne considèreront pas le Pakistan comme une priorité et qu'ils n'exerceront pas des pressions réelles sur Islamabad pour que les élections de 2007 soient véritablement libres et équitables. Tant que les militaires et les madrassas exerceront le pouvoir audelà de ses frontières, l'Afghanistan ne trouvéra jamais la paix." (Wall Street Journal, 10.05.06: Ch. Patten, "What Ails Afghanistan?)
\end{abstract}

(Source principale : Bulletin du CEREDAF)

mand, limogé pour ses liens supposés avec le trafic de drogue, sont assassinés.

Hâmed Karzaï participe à Bakou à une réunion de l'Organisation de Coopération Economique. Il y sera notamment question de la fourniture d'électricité à l'Afghanistan par l'Iran, le Tadjikistan et le Turkménistan.

L'Italie passe le commandement de l'ISAF à la Grande-Bretagne.

Le gouvernement afghan proteste contre l'interdiction par le Pakistan d'exporter du ciment vers l'Afghanistan.

Le gouvernement japonais promet une aide de 2,3 millions de dollars dans le domaine des réformes de la police pour les provinces de Bamiyan, Nangarhâr et Hérat. Le Japon a déjà fourni pour 5,9 millions de dollars d'aide à la police des provinces de Kaboul, Kandahâr et Balkh.

- Le 5: Jusqu'au 23 mai, les SuperEtendard du porte-avions Charles-deGaulle volent au-dessus de l'Afghanistan dans des missions d'appuie feu et de reconnaissance.

Un hélicoptère américain "Chinook" CH-47 s'écrase lors d'opérations de combat près d'Asadabad, chef-lieu du Kunar, causant la mort de ses dix occupants. L'accident n'est pas dû à des tirs ennemis, selon l'état-major américain.

Les forces de sécurité du Nangarhâr sai- sissent une grande quantité d'explosifs dans un autobus pakistanais en provenance de Peshawar.

Deux soldats italiens sont tués et quatre autres blessés par l'explosion d'une bombe au sud de Kaboul.

460 étudiants de la faculté de médecine de Kaboul reçoivent leur diplômes, dont 90 filles qui deviennent ainsi les premières diplômées en médecine après la chute des Tâlebân.

- Le 6: Le ministre hollandais des Affaires étrangères de passage en Afghanistan confirme l'envoi de 1600 soldats supplémentaires dans la province afghane d'Orouzgan dès juillet, et pour une durée de deux ans. Il indique que les forces néerlandaises y vont pour promouvoir le développement, et non pour faire la guerre. La présence militaire hollandaise atteinatteindra ainsi 1900 soldats.

Le Directeur du département pour la Promotion de la Vertu et de la Prévention du Vice de la province de l'Helmand sous le régime tâleb, est tué à Quetta (Pakistan).

Un sondage indique que $54 \%$ des Canadiens désapprouvent le déploiement des troupes canadiennes en Afghanistan contre 13 pour cent de plus à la mi-mars.

- Le 7: Le Pakistan annonce que tous les réfugiés afghans enregistrés ont encore jusqu'à trois ans avant de retourner dans leur pays selon un accord signé avec le HCR.

Une députée, Malalaï Djoya, est prise à partie par d'autres parlementaires après avoir condamné les atrocités commises par des modjahedin. Deux parlementaires, Mohamed Hussaïni, député de Ghazni, et Fazlullah Modjadidi, député du Logar, frappent un cameraman qui filme la scène. Hâmed Karzaĩ demande à la GrandeBretagne son assistance dans le domaine des forces aériennes.

Les gouverneurs de cinq provinces du Sud (Kandahâr, Helmand, Day Kundi, Orouzgan et Zâbol) décident de former une cellule de coordination régionale au plan de la Police.

Une explosion se produit à $500 \mathrm{~m}$ du consulat indien de Hérat sans faire de hlessés. La présence indienne en Afghanistan irrite le Pakistan qui accuse New Delhi de soutenir la rébellion baloutche.

- Le 8: Deux bombes explosent à Djalâlâbâd.

Le président Karzaï demande à ses nouveaux ministres de déclarer leurs biens et leur état de santé afin d'assurer la transparence du gouvernement.

- Le 9: Fauzia Uloumi, responsable du Département des femmes à Lachkargah (Helmand) échappe à un attentat.

- Le 10 : Visite surprise à Kaboul du ministre canadien des Affaires étrangères.

Les neuf Afghans qui avaient détourné un avion de la compagnie Ariana en Angleterre, en février 2002, obtiennent le 
statut de réfugiés.

- Le 11 : Les parlementaires espagnols approuvent l'envoi de 150 soldats en Afghanistan.

- Le 13: Le commandant des forces américaines en Afghanistan estime que l'influence des Tâlebân dans les provinces de Kandahâr, Orouzgân et Helmand est plus forte que l'année dernière à la même époque. Selon lui, la solution est "plus politique que militaire ",

- Le 14: 200 à 300 hommes devraient rejoindre en 2006 les militaires français pour aider au commandement de la région de Kaboul et à la formation des officiers afghans.

Le Président Karzaï aurait demandé au Pakistan de cla- rifier si les Tâlebân ont assassiné l'ingénieur indien sur ordre des services secrets pakistanais.

Une équipe de football des Provinces du Nord-ouest du Pakistan participe pour la première fois depuis 20 ans à un tournoi en Afghanistan

Le porte-parole de la présidence afghane indique que l'Afghanistan offre sa médiation pour contribuer à la réduction de la tension entre l'Iran et les Etats-Unis. Mais le porte-parole du ministère iranien des Affaires étrangères rejette cette idée.

Le 15: Dans le but de stabiliser la sécurité de la région frontalière Est, le gouvernement afghan commence le recrutement d'hommes des tribus comme forces paramilitaires.

Quatre des sept Tâlebân évadés de la prison de Pul-e Tcharkhi en janvier dernier ont été capturés en Bulgarie et en Ouzbékistan.

Un militaire français est tué au cours d'une opération de déminage de l'aéroport international de Kaboul.

Le parlement afghan vote contre le projet de tournée internationale du Trésor de Bactriane.

Le 17: Le parlement canadien approuve de justesse (par 149 voix contre 145 ) une prolongation jusqu'en 2009 , de la mission militaire canadienne en Afghanistan, au terme d'un débat assombri par la mort le même jour d'une Canadienne tuée à une vingtaine de kilomètres à l'ouest de Kandahâr.

- Le 18: Dans I'Helmand, la police afghane annonce avoir tué 40 Tâlebân lors d'un violent affrontement. Les forces de l'ordre ont 13 morts.

Une attaque suicide tue un soldat américain et blesse cinq autres à Hérat.

- Le 19: Au moins 39 personnes (la plupart étant des immigrants afghans clandestins) trouvent la mort dans un accident routier dans le sud de la Turquie.

Deux Français trouvent la mort au cours d'un engagement contre les Tâlebân dans la région de Kandahâr. Ailleurs, dans la province d'Orouzgan, un Américain est tué et six autres blessés.
Trois Mirage 2000 et une centaine d'hommes rejoignent le contingent français stationné sur l'aéroport de Douchanbé pour appuyer les opérations militaires en Afghanistan.

- Le 20: En visite à Assadabad, cheflieu de la province du Kunar, le président Karzaï accuse les services secrets pakistanais d'entraîner des rebelles et de les envoyer combattre en Afghanistan en leur assurant un soutien logistique. Islamabad rétorque qu' "il n'y a aucune vérité dans tout cela ».

- Le 21: La Wolesi Djirga rejette le budget proposé par le ministre des Finances après que celui-ci n'a pas accepté une augmentation des salaires des fonctionnaires.

Une voiture piégée explose dans l'est de Kaboul sur la route de Djalalabâd, faisant trois morts.

- Le 22 : La coalition bombarde un village du sud de l'Afghanistan faisant jusqu'à 60 Tâlebân tués et au moins 16 morts parmi la population civile. Le lendemain, Hâmed Karzaï convoque le commandant en chef des troupes de la coalition pour lui demander des explications.

- Le 23: Soixante-quatre personnes sont tuées dans la région de Murghab (Orouzgan) lors d'une attaque tâlebân.

- Le 24 : Le pays connaît parmi les plus importantes violences depuis le renversement du régime tâleb. Jusqu'à 336 personnes, des militants islamistes pour la plupart, ont trouvé la mort en quelques jours. Francesc Vendrell, l'envoyé en Afghanistan de l'Union Européenne précise que le déploiement de l'OTAN en Afghanistan selon le Chapitre $7 \mathrm{de} \mathrm{la} \mathrm{Charte} \mathrm{des}$ Nations Unies les autorise " à utiliser tous les moyens disponibles » pour restaurer l'ordre dans le pays.

- Le 25: Hâmed Karzaï nomme le maréchal Fahim comme son conseiller supérieur à la Sécurité. En conséquence, il perd son siège au Sénat.

Hâmed Karzaï fait un voyage surprise à Kandahâr pour tenter de rassurer la population. Jusqu'à 3000 personnes ont fui le district de Panjwaï ces derniers jours.

La Banque mondiale approuve une aide de 60 millions de dollars dont 40 millions seront consacrés aux services des eaux de Kaboul.

- Le 26: Un bus pakistanais transportant 22 passagers quitte Peshawar pour Djalalabâd marquant l'ouverture d'une liaison par bus entre le Pakistan et l'Afghanistan et ce pour la première fois depuis 27 ans. Jusqu'à présent seuls les camions circulaient entre les deux pays, taxis et minibus s'arrêtant de chaque côté de la frontière.

- Le 28: A Téhéran, Hâmed Karzaï et son homologue iranien signent sept accords portant sur les coopérations économique, juridique et culturelle dont la construction du chemin de fer KhwafHérat.

C'est à une très forte majorité que le Parlement dit non à l'ultra-conservateur Fazel Hadi Chinwari, en poste depuis septembre 2001. Les députés rejettent également deux autres candidats à la Cour suprême. Le 24, le Parlement avait accepté deux candidats et rejeté deux autres.

- Le 29: Jusqu'à cinquante Tâlebân présumés sont tués par un bombardement de la coalition internationale près de Kadjakaï (Helmand).

Emeute à Kaboul après la mort de quatre civils tués par des soldats américains à la suite d'un accident de la route. Deux manifestants sont tués, apparemment par des policiers afghans, lorsqu'ils tentent de pénétrer dans le quartier du palais présidentiel. Un couvre-feu est instauré deux nuits dans la capitale. Certains émeutiers portaient le portrait de Massoud. Le Parlement afghan demande que les soldats américains responsables de l'accident soient poursuivis en justice.

(Source: Bulletin du CEREDAF

\section{Marie-Rose Nicod}

Madame Marie-Rose Nicod est décédée à Lausanne le 4 juin 2006, dans sa $89^{\mathrm{e}}$ année.

Dans les années 1970, Marie-Rose Nicod découvre l'Afghanistan, un pays qui la marquera pour le restant de ses jours et auquel elle restera toujours fidèle. Profondément bouleversée par le drame qui frappe les Afghans et les Afghanes au moment de l'intervention soviétique, elle fonde en 1980 l'Association suisse des Amis de l'Afghanistan (AAA) qu'elle présidera pendant de longues années et dont elle restera l'inspiratrice. Grâce à l'infatigable initiative de sa présidente, l'Association obtient d'importants moyens financiers et humains qui lui ont permis et lui permettent toujours de s'associer à des projets d'aide humanitaire et à des programmes de développement dans des régions parmi les défavorisées: le Wardak et le Hazaradjat. Particulièrement sensible au sort des Afghanes, Madame Nicod a beaucoup oeuvré pour l'amélioration de leur situation par la formation de sages-femmes. L'AAA pour-suit son cuvre par la réalisation de projets porteurs d'espoir : construction de puits, vulgarisation agricole et reconstitution de vergers, éducation, vaccinations, dispensaires. La collaboration de l'AAA et son soutien à des ONG afghanes et françaises ont conduit au développement et au succès de ces projets.

Excellente photographe, Marie-Rose Nicod a signé un livre, Afghanistan (Innsbruck 1985), dont les illustrations témoignent de son talent et de sa sensibilité.

Micheline Centlivres-Demont 


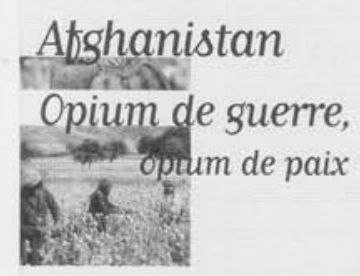

\section{Opium de guerre, opium de paix}

Les amis de l'Afghanistan pouvaient estimer avoir des idées claires et nuancées sur l'économie de la drogue dans ce pays et sur ses diverses incidences. Plusieurs ouvrages et articles avaient déjà traité du sujet, tels le livre de Stéphane Allix (Afghanistan aux sources de la drogue), la livraison du CEMOTI intitulée Drogue et politique ou, enfin, le pertinent article de Jean-Bernard Véron sur l'Opium en Afghanistan publié dans le $\mathrm{n}^{\circ} 115$ d'Afrique contemporaine (la revue montre ainsi que les problématiques d'aujourd'hui ne peuvent être circonscrites dans des espaces géographiques)

Malgré l'importance des données ainsi réunies, on s'est vite aperçu que l'on avait encore beaucoup à apprendre sur le sujet en lisant le livre minutieux, attentif, documenté d'Alain Labrousse intitulé : Afghanistan Opium de guerre opium de paix. Le titre, en luimême, donne à réfléchir puisqu'il suggère que la culture du pavot a pu avoir, au moins à court terme, un effet stabilisateur sur l'économie et la politique afghanes.

Malgré son volume, cet ouvrage parvient à tenir le lecteur en haleine, grâce à un style alerte et une soigneuse continuité dans la pensée, il fourmille en outre de renseignements statistiques et historiques.

Quand on l'a lu, le premier mouvement est de le relire tant il suscite de réflexions en chacun de ses chapitres. Il serait vain d'essayer de le résumer; contentons-nous d'évoquer quelques-unes des méditations qu'il inspire.

- Si la culture du blé est pour le paysan la garantie de son indépendance, mais dans la pauvreté, celle du pavot le condamne à la dépendance mais dans des conditions d'aisance relative. On comprend que, bon gré mal gré, les campagnes, les villages et une grande partie des villes afghanes, ont trouvé dans l'opium un remède à leur situation de précarité, une " bouée de sauvetage » économique et l'amorce d'une relance d'activités légales.

- Bien plus, les principaux clients des trafiquants d'opiacées (ces derniers n'étant afghans qu'en très faible minorité sauf, peut-être en Crimée) se trouvent dans les pays musulmans entourant l'Afghanistan et situés sur la route de transit des produits dérivés de l'opium. Il est donc vain de distinguer strictement entre les zones de production, de transit et de consommation.

- Les "cultures de substitution » ne sont pas une panacée. En fait on n'en à guère à proposer qui puissent détrôner le pavot. Il faut donc plutôt songer à une "économie des substitution " comportant reconstruction des infrastructures, crédit, microfi nance, amélioration du rendement des cultures légales, relance de l'artisanat. A ce propos, la distinction bien établie par l'auteur entre les " programmes » des grands acteurs institutionnels et les " projets " moins ambitieux mais très proches des besoins locaux et conçus parfois avec la participation d'ONG est judicieuse. Le livre montre la complémentarité des deux approches.

- La corrélation entre la vitalité de l'économie du pavot et celle des pouvoirs armés locaux est mise en évidence en plus d'un passage de l'ouvrage. On ne peut donc prétendre favoriser l'émergence d'institutions représentatives et délibératives sans aussi favoriser avec des moyens accrus et un doigté sans défaut l'émergence d'une économie licite. Négliger cette nécessaire concomitance revient à abandonner la représentation nationale à d'inquiétants réseaux de complicité.

- La mobilité d'une main d'œuvre souvent poussée hors de son terroir originel par la sécheresse ou l'insécurité, fait que la plupart des ouvriers agricoles et petits paysans afghans ont dû s'initier à la culture du pavot là où il est le plus intensément produit et appelle l'intervention de travailleurs saisonniers. A présent, et comme le montre le livre, un nombre croissant de régions où cette culture était inconnue la pratiquent désormais.

- L'économie de la drogue forme un ensemble international complexe dont il serait vain d'imaginer que le « moteur » se situe dans le seul Afghanistan. Penser réduire l'ampleur de cette économie en agissant dans ce seul pays est un leurre.

J'ajouterai, en dernier lieu, que l'auteur s'est voulu ce qu'il est, c'est-à-dire spécialiste chevronné des problèmes liés à la drogue dans le monde entier, membre actif d'ONG de développement mais non pas historien. Il lui a fallu cependant situer la problématique de la drogue dans le contexte historique afghan. Certains aspects narratifs de son ouvrage peuvent être sujets à discussion. Il reste que sa perception des évènements ayant affecté l'Afghanistan ces vingt dernières années paraît globalement juste. C'est donc avec la certitude de s'instruire qu'on ouvre ce livre.

Pierre LAFRANCE

"Afghanistan Opium de guerre, opium de Paix." d'Alain Labrousse. Editions des Mille et une nuits. 2005, 394p., ISBN 2842058976 